\title{
New Progress regarding the Use of Lactic Acid Bacteria as Live Delivery Vectors, Treatment of Diseases and Induction of Immune Responses in Different Host Species Focusing on Lactobacillus Species
}

\author{
Seria Masole Shonyela ${ }^{1,2 *}$, Guan Wang ${ }^{2}$, Wentao Yang ${ }^{2}$, Guilian Yang1\#, Chunfeng Wang1 ${ }^{1 \dagger}$ \\ ${ }^{1}$ College of Animal Science and Technology, Jilin Provincial Engineering Research Center of Animal Probiotics, Jilin Agricultural \\ University, Changchun, China \\ ${ }^{2}$ Ministry of Agriculture, Livestock and Fisheries, Dar es Salaam, Tanzania \\ Email: *henjemasole@yahoo.com, ${ }^{\star}$ seria.masole@sacidas.org, ${ }^{*}$ yangguilian@jlau.edu.cn, ${ }^{\dagger}$ wangchunfeng@jlau.edu.cn
}

\begin{abstract}
How to cite this paper: Shonyela, S.M., Wang, G., Yang, W.T., Yang, G.L. and Wang, C.F. (2017) New Progress regarding the Use of Lactic Acid Bacteria as Live Delivery Vectors, Treatment of Diseases and Induction of Immune Responses in Different Host Species Focusing on Lactobacillus Species. World Journal of Vaccines, 7, 43-75.
\end{abstract}

https://doi.org/10.4236/wjv.2017.74004

Received: November 23, 2017

Accepted: November 27, 2017

Published: November 30, 2017

Copyright $\odot 2017$ by authors and Scientific Research Publishing Inc. This work is licensed under the Creative Commons Attribution International License (CC BY 4.0).

http://creativecommons.org/licenses/by/4.0/

(c) (i) Open Access

\begin{abstract}
Lactobacillus species are non-spore-forming, gram-positive bacteria and lactic acid producing bacteria (LAPB) that naturally inhabit the human and animal gastrointestinal and mouth organs. The aim of this review was to evaluate the new progress regarding the use of Lactobacillus species as live delivery vectors, prevention, and treatment of pathogenic and metabolic diseases. Lactobacillus strains of probiotics have been extensively studied and have confirmed that they can absolutely improve performance as live delivery vectors, a treatment option of various diseases such as: Hemorrhagic cecal coccidiosis in young poultry, hypertension, avian flu, obesity, diabetes, Derzsy's disease or parvovirus infection, human immunodeficiency virus infections, irritable bowel syndrome, gastrointestinal disorders, Fungal infections, vaginal eubiosis, fish and shellfish species diseases. We give you an idea about that Lactobacillus species have been proficient in preventing and treating both disorders in animal models and some are used for clinical trials. We present the most current studies on the use of Lactobacillus strains that had an impact on an effective immune response to a specific antigen because a variety of antigens have been expressed. Therefore Lactobacillus strains can be considered as good candidates because of its potential for diseases treatment and vaccine development as heterologous protein secretion to date.
\end{abstract}




\section{Keywords}

Lactobacilli, Probiotics, Lactic Acid, Live Delivery Vectors, Treatment, Immune Responses

\section{Introduction}

Lactic acid bacteria (LAB) are gram-positive bacteria and nonpathogenic. They are considered to be generally regarded as safe (GRAS) organisms [1] [2] and daily ingested by humans playing significant roles as health-promoting probiotics which is the most important point, to improve general health and protect from different kinds of illness [3] [4] [5] [6]. Also they are used for production of food and feed throughout the world [7] [8] [9] [10] [11] because of their wide use in the food industry for the production and the preservation of fermented products such as whole-grain sourdough bread or sourdough fermentation [12] [13]. Daily consumption of dairy yogurt having Lactobacillus paracasei, and heat-treated Lactobacillus plantarum possibly is successful alternative to improve immune function by enhancing IFN- $\gamma$ concentration and NK cell function [14]. Probiotics can also survive on non-dairy foods under ambient storage conditions [15].

Recent studies present that Lactobacillus species have been used as Probiotics for the prevention or treatment of a range of diseases associated with diarrhea [16] [17] [18]. Lactobacillus plantarum assimilates cholesterol and modulates $A B C A 1, C D 36, N P C 1 L 1$ and $S C A R B 1$ in vitro [19], immune function [20], inflammatory bowel disease [21] [22] [23], and respiratory viral infection [24]. In addition, probiotic bacteria in the Lactobacillus genera are capable to have therapeutic effects in the patients of psychological disorders, such as depression, anxiety, and memory [25] [26] [27].

The move towards for controlling the immune hyper-response in today's situation for the most part appoints the natural ways which assist the body to uphold the immune homeostasis and do not cause any side effects [28], such as use of probiotics in the company of combination of a non-digestible food ingredient that promotes the growth of beneficial microorganisms in the intestines. Quite a lot of research projects have used Lactobacillus strains as vectors including our laboratory (Jilin Provincial Engineering Research Center of Animal Probiotics) and other probiotics research projects in the world [29]-[35]. In addition Lactobacillus strains are well thought-out to be competent candidates for delivery systems of heterologous proteins and for the development of novel, safe production [36].

In this review, we evaluate the new progress regarding the use of Lactobacillus strains as live delivery vectors. An assortment of molecular tools has been developed to professionally express therapeutic molecules and antigens at different cellular localizations. We report systems developed to use Lactobacillus strains as a live vaccine, treatments and the effects of such an antigen presentation 
mode on both systemic and mucosal immune system.

\section{Methods}

The review search and writing were performed from March $8^{\text {th }} 2017$ until August $25^{\text {th }} 2017$.

\subsection{The Inclusion Criteria Were as Follows}

- The recent year's research studies from 2015 to 2017 published in English language regarding the use of newly developed technology and analytic methods of lactic acid bacteria as live delivery vectors, treatment of diseases, and immune responses vaccines in different host species focusing on Lactobacillus species.

- Included Clinical studies and Experimental studies, whether used animals model, human or patient in hospital and aquaculture focusing on Lactobacillus species.

- When the same groups of animal model or human and the same strain of Lactobacillus species were reported in multiple papers, only the most recent and complete paper was selected to avoid overlap.

- Some systemic reviews when needed in the introduction and discussion.

\subsection{Exclusion Criteria}

- Studies that met the following criteria were excluded: If comprising only conference abstracts were excluded due to the lack of sufficient data.

- If outcomes were presented in other ways such as figures without explanations of outcomes and if not meeting the inclusion criteria described above.

\subsection{Article Search Strategy}

Researchers performed searches of the electronic databases of:

- Elsevier

(https://www.journals.elsevier.com/the-lancet-infectious-diseases/),

- PubMed (http://www.ncbi.nlm.nih.gov/pubmed/),

- Springer, Cochrane Library, Scopus, Ovid (Medline, EMBASE, PsycINFO), Orbis, and Web of Science

Data from 2015 to 25 August, 2017.

The following key words were used: "lactic acid bacteria," "Lactobacillus," "probiotics," as live delivery vectors, treatment of diseases, and immune responses vaccines in different host species." We also checked the references listed at the end of each publication to identify additional studies.

\subsection{Data Collection}

Whichever eligible studies with regard to the health-promoting effect of Lactobacillus species, as probiotics for companion animals, livestock, poultry and aquaculture were collected on a modified form and examined by the second and 
third authors. The form included study's author(s), publication date, Lactobacillus Strain, probiotic dosage, and treatment or vaccination outcomes. If the study data were unclear, such as if only abstract available but full text not easy to get to or if the outcome not saying anything on how long lasting immunity induced by the recombinant Lactobacillus strains we attempted to contact the corresponding author to obtain further information in detail.

\subsection{Effectiveness Analysis}

Treatment and vaccination outcomes were the major variables used to confirm currently the efficacy of Lactobacillus strains as probiotics in the treatment and vaccination of difference diseases.

\section{Results}

In the initial search we read about 182 articles about, Lactic acid bacteria were reviewed. But, no more than 168 Studies involving Lactobacillus species met the selection criteria since some data were unclear, incomplete, or too old to be included in this review.

\section{Lactobacillus Strains as Health Promoting Probiotics}

Lactobacillus species are non-spore-forming Gram-positive bacteria and lactic acid producing bacteria (LAPB) that naturally inhabits the human and animal gastrointestinal and mouth organs [37] [38] [39]. Many genetic tools have been developed and many of $L$. species its complete genome were recently sequenced [20] [37] [40] [41] [42]. Lactobacillus species have met the criteria necessary to consider them as probiotics and they also have nutritional and therapeutic effects, regarded as probiotics because they are able to survive and thrive throughout the gastrointestinal conditions and present their beneficial effects. It is therefore important to understand their mechanisms of action in order for them to be used both prophylactic and as treatment options for different diseases [41] [42] [43]. Lactobacillus species are an important part of normal intestinal microbiota of various mammalian species and is also the best characterized and widely commercialized probiotic because they provide an affordable means for prevention and treatment of various infectious, allergic and inflammatory conditions as demonstrated in numerous animal and human studies [44] [45]. The in vitro study by [46] about comparing Antibacterial activity of Lactobacillus plantarum Strains (Os13 and Kor14) showed strong antimicrobial activities against a wide range of potential pathogens especially $L$. monocytogenes since were active against potential pathogens and each Lactobacillus plantarum strains produced broad spectrum of antimicrobial agents. However, it is known that the health-promoting properties of Lactobacillus strains probiotics change extensively in response to their culture conditions. This is because may results in profound variability in probiotic functionality even when the strain remains unchanged, such as the IL-10 and IL-12 modulatory activity of L. plantarum 
OLL2712 changes according to culture conditions [22] see Table 1.

\subsection{Management of Gastrointestinal Disorders}

In probiotic aspects, Lactobacillus species confirmed helpful roles in the commencement of the gut mucosal immune system [47] [48]. Supplementation with specific strains of Lactobacillus species as probiotics has been revealed to have modulatory effects on intestinal [1] [49] [50] [51] [52]. Efficient expression systems have already been developed for controlled and targeted production of the desired antigen for exposure to the gastrointestinal mucosal immune system [53] [54] [55] as have been shown to provide beneficial health effects to the host by replenishing natural gastrointestinal flora. In vitro studies have shown that Lactobacillus species supplementation protected the pigs against ETEC K88 infection by enhancing immune responses which attenuated intestinal damage, improved the performance and nutrient digestibility of pigs [43]. Also Lactobacillus reuteri 15007 strain modulated intestinal host defense peptides (HDP) expression and improved the gut health of neonatal piglets [56].

The study by Olek showed that there was no statistically significant differences between the Lactobacillus plantarum DSM 9843 (LP299V) and placebo groups in the prevention of antibiotic-associated gastrointestinal symptoms in children and reduced the incidence of diarrhea [57]. The study about the use of fermented dairy drink containing probiotic Lactobacillus paracasei CNCM I-1518

Table 1. Examples of Lactobacillus species as bacterial vaccine vectors or treatment against different pathogens or tumor.

\begin{tabular}{|c|c|c|c|c|}
\hline $\begin{array}{l}\text { Vector/attenuation } \\
\text { or complementation }\end{array}$ & Antigen/target & $\begin{array}{l}\text { Animal model/ } \\
\text { Inoculation route }\end{array}$ & Detected immune response/indicator & References \\
\hline \multirow{5}{*}{$\begin{array}{l}\text { Lactobacillus } \\
\text { plantarum }\end{array}$} & $\begin{array}{l}\text { H9N2 avian influenza } \\
\text { virus (AIV) }\end{array}$ & Mouse/Oral & $\begin{array}{l}\text { IgG, sIgA, CD4+, CD } 8+\text { T cell proliferation, } \\
\text { IgA, and IFN }-\gamma^{+}\end{array}$ & [29] [78] \\
\hline & Staphylococcus aureus & Mouse/Oral & sIgA, IFN- $\gamma /$ IL-4 & [45] [133] \\
\hline & Listeria monocytogenes & Mouse/Oral & IgG, IL-10 and IL-12 & [46] \\
\hline & E. coli & Mouse/Oral & SIgA, IFN-, IL-12, TNF_, and IL-6 & [91] \\
\hline & Parvovirus & Mouse/Oral & $\mathrm{CD} 11 \mathrm{c}^{+}, \mathrm{CD}^{+} \mathrm{CD}^{+}, \mathrm{CD}^{+} \mathrm{CD}^{+}, \mathrm{sIgA}$ and $\operatorname{IgG}$ & [34] \\
\hline \multirow{2}{*}{$\begin{array}{l}\text { Lactobacillus } \\
\text { rhamnosus }\end{array}$} & $\begin{array}{l}\text { S. aureus, } S . \text { typhimurium, and } \\
\text { E. coli, inflammatory damage }\end{array}$ & Mouse/Oral & $\begin{array}{l}\text { proinflammatory cytokines IL- } 8, \text { TNF- } \alpha \text {, } \\
\text { IL- } 12 \text { p } 70, \text { IL- } 6 \text { and IL- } 1 \beta, \mathrm{CD} 3^{+} \mathrm{CD} 4^{+} \mathrm{IFN}-\gamma^{+} \text {, } \\
\text { and } \mathrm{CD} 3^{+} \mathrm{CD} 4^{+} \mathrm{IL}-10^{+} \mathrm{T} \text { cells }\end{array}$ & $\begin{array}{l}{[45][98]} \\
\quad[99]\end{array}$ \\
\hline & human rhinovirus & $\begin{array}{l}\text { Gnotobiotic } \\
\text { pigs/Oral }\end{array}$ & $\mathrm{CD} 4^{+} \mathrm{T}-$ bet ${ }^{+} \mathrm{IFN} \gamma^{+} \mathrm{T}$ cells & [134] \\
\hline $\begin{array}{l}\text { Lactobacillus } \\
\text { johnsonii }\end{array}$ & indigestion, abdominal pain & human & $\begin{array}{l}\text { Th1 cells }\left(\mathrm{CD} 45 \mathrm{RO}^{+} \mathrm{CD} 183^{+} \mathrm{CD} 196^{-}\right) \text {and } \\
\text { cytotoxic } \mathrm{CD} 8^{+} \mathrm{T} \text { cells }\end{array}$ & [109] [112] \\
\hline $\begin{array}{l}\text { Lactobacillus } \\
\text { reuteri }\end{array}$ & food allergy & Mouse/Oral & $\begin{array}{l}\text { IgE, Th } 1 \text { and } 2 \text {, IFN-c and IL- } 4 \text {, IFN-c, } \\
\text { GATA } 3 \text { and T-bet IL-10, TGF-b and Foxp3, } \\
\text { IL-10-CD11c+CD103+ }\end{array}$ & [123] \\
\hline $\begin{array}{l}\text { Lactobacillus } \\
\text { acidophilus }\end{array}$ & $\begin{array}{l}\text { Salmonella typhimurium, } \\
\text { Staphylococcus aureus, and } \\
\text { Pseudomonas aeruginosa }\end{array}$ & Mouse/Oral & IgA, IL-12, IL-8, IL-6, and IL-1, & [94] \\
\hline
\end{tabular}


to prevent Antibiotic-associated diarrhea showed the importance of LactobacilIus strains in improving health [58]. Also older hospitalized patients treated with antibiotics lead to considerable cost savings, in addition to Infants hospitalized with rotavirus disease were treated with probiotics containing both Bifidobacterium longum BORI and Lactobacillus acidophilus AD031, Symptoms such as duration of fever, frequency of diarrhea, and frequency of vomiting tended to be ameliorated by the probiotic treatment [59].

Lactobacillus johnsonii could decrease intestinal Campylobacter jejuni burdens as offer valuable prophylaxis and treatment of $C$. jejuni induced intestinal, pro-inflammatory immune responses in vivo [60] and systemic immune responses in animal models and forms the basis for animal and human studies with vaccines [49] [50] [51] [61]. The study of in vitro and in vivo antagonistic activity of new probiotic culture against Clostridium difficile and Clostridium perfringens, exhibited immunomodulatory activity and among hospitalized adults, Lactobacillus probiotics reduced the risk of clostridium difficile-associated diarrhea when taken concomitantly with antibiotics, with no evident increase in adverse events [62] [63]. Although it shown that in elderly orthogeriet-ric patients on antibiotic do not support the use of Probiotic containing Lactobacillus casei, Lactobacillus bulgaricus, and Streptococcus thermophiles (ACTIMEL) for reducing the incidence of Clostridium difficile associated diarrhoea (CDAD). Regardless of these patients being at high risk for developing CDAD, failure to reveal a significant advantage makes this infection control strategy difficult to give good reason for [64]. Some studies have revealed that they give a helpful effect by production of antimicrobial molecules and promoting secretion of immunoglobulin IgA which are capable of inhibiting some intestinal pathogens [65] [66]. Evaluation of Lactobacillus reuteri L26 was concluded that has an antiviral effect on PCV2 in the intestine as immune response against porcine circovirus type 2 infections in germ-free mice significantly up-regulated gene expression of chemokines, interferon (IFN)- $\gamma, \operatorname{IgA}$ and PIgR in the ileum was accompanied by higher proportion of natural killer cells and higher proportion of CD19+ lymphocytes in the MLN [67].

\subsection{Prevention and Management of Hypertension}

Several animal and human studies have observed the association between the oral and gut microbiome with blood pressure [68]. The study confirmed a considerable reduction in microbial richness and multiplicity in the presence of hypertension. As well studies have confirmed a changed microbial composition and modified metabolite profiles, suggesting a role for microbial dysbiosis and microbial metabolites which including use of Lactobacillus species for hypertension treatment [66] [69] [70]. Some studies showed the effectiveness and safety of Lactobacillus species on the treatment of hypertension. As were observed in hypertensive patients increased myeloid inflammatory cells CD14+ cells, CD11b+ cells and Th17 cells, increased in CD4+ IL17+ cells. An increase 
in the Th17 cells was tremendously appropriate finding because demonstrated that levels of these cells were regulated by gut-intrinsic mechanisms that generate pro-inflammatory cytokines for instance TGF- $\beta 1$, TNF- $\alpha$, IL- $1 \beta$ and IL- 6 [71] [72] [73].

Oral administration of recombinant Lactobacillus plantarum NC8 considerably decreased systolic blood pressure, increased level of nitric oxide, as well as decreased levels of endothelin and AngII in plasma, heart, and kidney, representing the potential application of recombinant Lactobacillus plantarum in the treatment of hypertension [69]. In additional; an oral, genetically-modified strain of the probiotic Lactobacillus was used to treat rats with high blood pressure in the lungs, which resulted in improved heart contractility, reduced blood pressure, and reduced heart wall thickness. Also researchers genetically engineered strains of Lactobacillus species, to express and secrete Ang-(1-7), tested in an animal study and was effectively treat pulmonary hypertension [69]. Fermented whey from bovine milk with several Lactobacillus species to free antihypertensive peptides from whey, and found that Lactobacillus helvelticus fermented whey hydrolysates contained peptides which showed strong angiotensin 1-converting enzyme inhibition. These peptides, at least in part, contributed to the ACE inhibitor effect of the fermentate. Whey fermented with Lactobacillus brevis also contained a potent ACE inhibitor peptide [74].

\subsection{Prevention and Management of Respiratory Tract Disorders}

The studies in the infant mice and immunocompromised-malnourished mice showed the improvement of the resistance to primary respiratory syncytial virus (RSV) infection, and secondary pneumococcal pneumonia. In relationship with the protection against RSV-pneumococcal superinfection, the study revealed that peptidoglycan from Lactobacillus rhamnosus CRL1505. Considerably enhanced lung $\mathrm{CD} 3^{+} \mathrm{CD} 4^{+} \mathrm{IFN}-\gamma^{+}$, and $\mathrm{CD} 3^{+} \mathrm{CD} 4^{+} \mathrm{IL}-10^{+} \mathrm{T}$ cells plus $\mathrm{CD} 11 \mathrm{c}^{+}$SiglecF $\mathrm{F}^{+} \mathrm{IFN}-\beta^{+}$alveolar macrophages with the resulting of increases of IFN- $\gamma$, IL-10, and IFN- $\beta$ in the respiratory tract [75] [76]. Nasal administration of Lactobacillus rhamnosus CRL1505 strain to malnourished mice under recovery reduced quantitative and qualitative alterations of $\mathrm{CD} 4^{+} \mathrm{T}$ cells in the bone marrow, thymus, spleen and lung as well, CRL1505 treatment increased $\mathrm{Th}_{2}$-cytokines; interleukin 10 and 4 in respiratory and systemic compartments [77]. The study of immunization with recombinant Lactobacillus plantarum expressing 3M2e-Fc demonstrated the markedly reduction of the viral load in the lung and protected against $\mathrm{H} 1 \mathrm{~N} 1$ influenza virus. As well as mouse-adapted H9N2 avian influenza virus (AIV) challenge in BALB/c mice, also provided effective protective immunity against infection with homologous and heterologous influenza viruses in a mouse mode and were seem to lower respiratory tract infections [29] [78] also see Table 1. The study of the effect of a probiotic supplement on the incidence of upper respiratory tract infections [61], and the metabolism of aromatic amino acids after exhaustive aerobic exercise in trained ath- 
letes daily supplementation with probiotics was found to be associated with a lower frequency of URTIs in athletes and seems to be beneficial in increasing training efficacy [79]. Respiratory viral infection via metabolic reprogramming and immune cell modulation by Lactobacillus johnsonii [24], Avian Infuenza infection [34] [80] [81]. In additional Lactobacillus plantarum GBLP2 isolated from Korean fermented vegetable exhibited preventive effect against the influenza virus infections in mice [82].

\subsection{Management of Chronic Constipation}

Differentiations in the composition of the intestinal microbiota have been confirmed when constipated patients and healthy controls have been evaluated in different studies and have shown that Lactobacillus may play an essential role in the pathogenesis of chronic constipation [83]. Lactobacillus species as probiotics could reduce the migrating myoelectric complex (MMC) period and speed up small intestinal transit. Especially some of a good number studied strains such as Lactobacillus casei, Lactobacillus rhamnosus, Lactobacillus acidophilus, showed a significant role of reducing the level of intraluminal $\mathrm{pH}$ and promoting colonic peristalsis which is supportive for changing stool that could significantly increase the frequency of defecations and the softness of the stool [84] [85] [86]. The assessment of the effectiveness of Lactobacillus casei rhamnosus Lcr35 (Lcr35) in the management of functional constipation in children showed a significant increase in the frequency of defecation in both the placebo group and in the Lactobacillus casei rhamnosus Lcr35 group [87].

\subsection{Prevention and Management of Hypercholesterolaemia}

Recent studies have shown the potential use of lactobacillus species as part of the strategies in prevention and management of hypercholesterolaemia. Eating yogurt or taking capsules containing the Lactobacillus strain for example Lactobacillus reuteri NCIMB 30242 give the impression to decrease low-density lipoprotein cholesterol in adults with high cholesterol. Furthermore treatment of HT29 cells with Lactobacillus plantaram after prolonged exposure to cholesterol source it was demonstrated that was associated with up-regulation of $A B C A 1$, restoration of $C D 36$ to basal level and down-regulation of Neimann-Pick C1-Like 1 (NPC1 L1). Also Lactobacillus fermentum NCIMB 5221 and Lactobacillus fermentum NCIMB 2797 have the potential via various modes of action to lower cholesterol [88] [89] [90].

\subsection{Enhancement of Anti-Inflammatory Response}

Lactobacillus plantarum L9 and Lactobacillus acidophilus LA were shown to some studies that have significant inhibition of E. coli adhesion and cell internalization to the enterocyte monolayer surface as shown in Table 1 . Such as the study by [91] made known that Lactobacillus plantarum L9 and Lactobacillus acidophilus LA have good ability to adhere to Caco-2 cells. As well treatment 
with mixed lactic acid bacteria increased the anti-inflammatory factor and the secretion of $\operatorname{sgA}$ in the intestine of mice infected with Staphylococcus aureus inhibited the inflammation [45] [92] [93] [94] [95]). Lactobacillus fermentum HY01 strain in some studies showed that had significant preventive effects in dextran sulfate sodium induced-colitis; at the same time, it can efficiently reduce edema, inflammatory cells infiltration, and colon mucosa injury. In addition to play a significant function in the down-regulation of concentrations of pro-inflammatory factors (IFN-, IL-12, TNF_, and IL-6) in particular shows a hopeful prevention for I_B_ degradation, decreases the protein levels of iNOS and COX-2 along with inhibition of NF-_B p65 phosphorylation cascades [17] [96] [97]. The outcome from some studies obtained from Lactobacillus rhamnosus GG, Lactobacillus rhamnosus KLSD, Lactobacillus helveticus IMAU70129, and Lactobacillus casei IMAU60214 demonstrated that strains induced early proinflammatory cytokines for example IL-8,TNF- $\alpha$, IL-12p70, IL-6 and IL-1 $\beta$. Phagocytosis and bactericidal activity of macrophages against various pathogens, such as $S$. aureus, $S$. typhimurium, and E. coli, were increased by pretreatment with Lactobacillus [45] [98] [99].

\subsection{Management of Lactose and Glucose Intolerance}

Population for whom lactose acts like an osmotic, non-digestible carbohydrate for the reason that they have a low amount of intestinal lactase; Lactose intolerance is a problem for a large part of the world. The predigestion of lactose could decrease the symptoms related with lactose intolerance in vulnerable persons. For the duration of fermentation of milk and yogurt having Lactobacillus acidophilus, generate lactase that hydrolyses lactose to galactose and glucose. Lactobacillus species probiotics have been revealed to improve lactose digestion and intolerance in some studies [100]. Glucose intolerance was to some extent prevented by supplementation of Lactobacillus kefiri treatment changed Bacteroidetes and Firmicutes profiles. It was demonstrated that the administration of Lactobacillus kefiri prevents the deleterious effects of fructose-rich diet intake, therefore improved metabolic disorders [101].

\subsection{Prevention and Management of Cancer}

Lactobacilli Strains play significant function in cancer etiology for the reason that they can manipulate several elements of the intestinal tract such as development, immune homeostasis, physiology and metabolism. Laboratory-based studies have demonstrated that Lactobacilli Strains contains strong anti-tumor effects [102]. Many studies of anti-tumor vaccines of Lactobacillus species using mouse models have been employed. Lactobacillus biotherapeutic for colorectal cancer (CRC), inhibited cancer-causing events, based on anti-CRC proliferative effect, immune modulation and metabolic activity, in vitro and in vivo, using a genetically-induced animal CRC model [103]. The study of inhibitory effects of probiotic Lactobacillus on the Growth of Human Colonic Carcinoma Cell Line 
HT-29 showed that Lactobacillus can inhibit the growth of colonic carcinoma cells and may lead to apoptosis. Live Lactobacillus acidophilus and Lactobacillus rhamnosus GG, Lactobacillus casei, Lactobacillus reuteri has been confirmed to induce apoptotic cell death in both murine and human colon carcinoma cell lines as well as an experimental tumor model [104] [105] [106] [107] [108].

\subsection{Management of Diabetes and Obesity}

Current review study revealed that construction of a recombinant strain of Lactobacillus gasseri, Lactobacillus paracasei elicits various health benefits through its antimicrobial activity, bacteriocin production, and immunomodulation of the innate and adaptive systems therefore had significantly reduced blood glucose levels and increased insulin levels [109] [110] [111]. Also Lactobacillus species such as: Lactobacillus acidophilus, Lactobacillus plantarum, Lactobacillus paracasei, Lactobacillus bulgaricus have been known to improve obesity-associated metabolic problems. Researchers said this may be attributed to interactions with obesity-promoting bacteria in the gut and direct modulation of host immunity and gut barrier function. Administration of Lactobacillus johnsonii N6.2 considerably decreases the happening of indigestion, abdominal pain, and cephalic syndromes were observed. Additionally, some studies demonstrated that monocytes and natural killer cell numbers were increased significantly and an increase of circulating effector Th1 cells $\left(\mathrm{CD} 45 \mathrm{RO}^{+} \mathrm{CD} 183^{+} \mathrm{CD} 196^{-}\right)$and cytotoxic CD ${ }^{+}$ T cells subset was observed in the Lactobacillus johnsonii N6.2 group [109] [112].

\subsection{Management of Irritable Bowel Syndrome}

The thoroughly assessment and a meta-analysis studies of the effect of Lactobacillus in treating the irritable bowel syndrome was found to be more effective with a significantly higher rate without any side effects. The researchers noted that abdominal distension was significantly reduced by probiotics containing, Lactobacillus casei, or Lactobacillus plantarum and flatulence, pain and bloating caused by IBS were significantly reduced by Lactobacillus acidophilus, have concluded that some Lactobacillus are beneficial in improving symptoms and reducing the risk of persistent symptoms in some patients with Irritable bowel syndrome, even though the overall effect is modest [113] [114] [115].

\subsection{Prevention and Management of Fungus}

Lactobacillus acidophilus DDS-1, Lactobacillus casei, Lactobacillus plantarum, Lactobacillus salivarius, Lactobacillus rhamnosus, and Lactobacillus brevis are acknowledged to inhibit the growth of Candida albicans by enhancing the immune system, reduce the candida overgrowth and by taking repeatedly prevents the reappearance of yeast infections in future [58].

\subsection{Prevention and Management of Vaginal Infections}

Lactobacillus species are thought to be a valuable biomarker and agents that can 
promote various aspects of vaginal health such as Lactobacillus crispatus, Lactobacillus jensenii, Lactobacillus iners and Lactobacillus gasseri [116] [117] [118]. Many types of pathogens for vaginal infections such as; candidal vaginitis, vaginal eubiosis prevention by killing dysbiotic microbes with acidic lactic acid is one of the claims often made specifically for lactobacillus strains probiotics, formulated with multiple or single strains. Such as (Lactobacillus plantarum, Lactobacillus fermentum, Lactobacillus rhamnosus GR-1, Lactobacillus reuteri RC-14, Lactobacillus acidophilus, L. brevis, L. gasseri, L. crispatus,) such as establishment of vaginal eubiosis by killing dysbiotic microbes, and many types of pathogens, with acidic lactic acid, have been evaluated in several randomized clinical trials that it can prevent vaginal infections, alone or as adjuncts to antibiotic therapy, and for the prevention of bacterial vaginosis [119] [120] [121] [122].

\subsection{Prevention and Management of Nematodes}

One study assessed some aspect of the currently characterization of Lactobacillus strains belonging to Lactobacillus delbrueckii sub species bulgaricus and lactis demonstrated that $L$. delbrueckii subsp. bulgaricus in diet exerted advantageous effects on nematodes, both L. delbrueckii subsp. lactis strains affected lifespan and larval development of nematodes, galactose metabolic capabilities and $L$. delbrueckii subspecies bulgaricus strain confirmed promising probiotic features [52]. Treatment with Lactobacillus rhamnosus JB-1 strain significantly enhanced worm expulsion in resistant C57BL/6 mice, and this was associated with increases in goblet cell numbers, IL-10 levels, and epithelial cell proliferation [52].

\subsection{Prevention and Management of Allergy}

One study assessed some aspect of the consequence of Lactobacillus reuteri in opposition to food allergy was examined in ovalbumin (OVA)-sensitized BALB/c mice study. It was demonstrated that Lactobacillus reuteri possesses anti-allergic activities by means of promoting tolerogenic immune responses, modulating enteric flora, as a result worsen profile of enteric flora, and attenuated allergic diarrhea was re-established by Lactobacillus reuteri also supplementing infant with Lactobacillus rhamnosus GG offered as management of cow milk allergy [123].

\section{Lactobacillus species as Recombinant Strain, Elicit Specific Mucosal and Systemic Immune Responses}

Recombinant probiotics can act as a vaccine arming the host immune system to deal with pathogens. To develop a safe, effective, and convenient vaccine for the prevention of pathogenic, and metabolic problem require to construct recombinant lactic acid bacteria such as lactobacillus strains that can express the foreign virus protein, bacteria or cell antigen hence trigger the mucosal and systemic immune responses. Many experimental and clinical studies of Lactobacillus strains as probiotic have reported that had an impact on an effective immune 
response to a specific antigen because a variety of antigens have been expressed in Lactobacillus strains, summarized in Table 1.

Recombinant Lactobacillus strains are known to elicit specific mucosal and systemic immune responses against antigens recent studies demonstrated that lactic acid is a major antimicrobial factor produced by Lactobacillus species such as: Recombinant Lactobacillus plantaram studies The study by [124] about assessment of recombinant Lactobacillus plantarum expressing SO7 of Eimeria tenella fusion DC-targeting peptide were significantly reduce pathological damage in cecum in broiler chickens, that means could become a hopeful oral vaccine candidate against E. tenella infection. [22] [35] [125] [126].

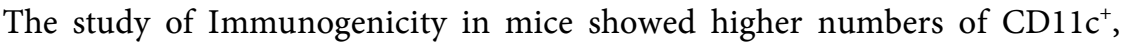
$\mathrm{CD}^{+} \mathrm{CD}^{+}, \mathrm{CD}^{+} \mathrm{CD}^{+}$, and interferon gamma- and tumor necrosis factor alpha-expressing spleen lymphocytes in mice immunize with recombinant Lactobacillus Plantarum NC8 Expressing Goose Parvovirus VP2 Gene than those in the control groups [32]. A recombinant Lactobacillus plantarum NC8 strain expressing NP-M1-DCpep from H9N2 AIV has been studied in a mouse model and exhibited significantly increased $\mathrm{T}$ cell-mediated immune responses and mucosal sIgA and IgG levels, which provided protection against H9N2 AIV challenge, in additional intranasal administration induced stronger immune responses and provided effective protection against challenge with the H9N2 virus and $L$. plantarum vaccine vector expressing hemagglutinin provided protection against $\mathrm{H} 9 \mathrm{~N} 2$ challenge infection [34].

Recombinant $L$. plantarum expressing 3M2e-Fc elicited Peyer's patch (PP) DC activation, improved the number of gamma interferon (IFN- $\gamma$ )-producing $\mathrm{T}$ cells and increased the frequency of $\mathrm{CD}^{+} \mathrm{IFN}-\gamma^{+}$cells in the mesenteric lymph nodes and enhanced specific sIgA secretion [34].

Recombinant Lactobacillus plantarum with surface displayed hemagglutinin subunit 2 (HA2) alone or together with heat-labile toxin B subunit (LTB) from enterotoxigenic Escherichia coli in Balb/c mice increased the percentages of $\mathrm{B}_{220^{+}} \mathrm{IgA}^{+} \mathrm{B}$ cells in peyer patch, in consistent with elevated production of mucosal SIgA antibody determined by ELISA [31]. Other Lactobacillus species that have been studied for recombinant are: Recombinant Lactobacillus plantarum ULAG11 strain was transformed with pLuc2 in millet seed [127], Recombinant Lactobacillus rhamnosus and Lactobacillus fermentum [128] [129].

Administration of recombinant Lactobacillus casei expressing F4 (K88) fimbrial adhesin FaeG in conjunction with a heat-labile enterotoxin A (LTAK63) and heat-labile enterotoxin B (LTB) of enterotoxigenic Escherichia coli as an oral adjuvant in mice showed significantly higher levels of FaeG-specific serum IgG and mucosal sIgA, as well as the proliferation of lymphocytes [130] [131] [132].

\section{Lactobacillus species as Mucosal Delivery Vectors for DNA Vaccines and Therapeutic Proteins}

The approach of using live bacterial cells as means of transportations to deliver 
recombinant antigens has appeared in excess of the past two decades as an interesting option for the improvement of new vaccines. Lactobacillus species are known to influence the immune response in a strain-dependent manner; therefore, they are good candidates for developing innovative oral vectors, comprising good options to reduce the strength of pathogens, meant for mucosal delivery approaches [124] [130]. Lately, ever-increasing confirmation supported that Lactobacillus strains expression systems, through expression and delivery of antigens/adjuvant, are hopeful oral vaccine vectors, due to their: efficient delivery of immunogens to the mucosal inductive locations, exceptional safety, reduced antigen degradation and prevention of protein purification.

On the use of Lactobacillus species as mucosal delivery vectors for therapeutic proteins and DNA vaccines such as expression signals and host strains, for the heterologous expression of therapeutic proteins such as antigens, cytokines and enzymes [135] [136]. Resulting recombinant Lactobacillus strains have been tested successfully for their prophylactic and therapeutic effects in different animal models: especially, anti-oxidative Lactobacillus casei, Lactobacillus plantaram and Lactobacillus reuteri strains were constructed and tested in different study models as delivery vehicles for presentation to the mucosa of compounds with pharmaceutical attention, mainly vaccines [35] [124] [130] [137]. The viability of shuttle vector for heterologous protein expression in Lactobacillus casei TISTR1341 was determined that is able to modulate the host response through cloning in pRCEID-LC7.6, the gene encoding the nucleocapsid protein (NP), from the influenza A virus under the control of the homologous promoter from the lactate dehydrogenase gene. Lactobacillus casei strains carrying this recombinant plasmid was made known to productively express the NP protein [135]. The study by Lin et al showed that, recombinant Lactobacillus acidophilus (LA-ET) was safe in a cell model and excluded EHEC O157:H7 from LoVo cells at rates of nearly 94 in exclusion and $60 \%$ in competition assays. Lactobacillus acidophilus induced higher levels of specific mucosal and systemic antibody responses and improved interferon- $\gamma$ and interleukin- 4 and -10 productions, which was coupled with assorted helper $\mathrm{T}$ (Th1/Th2) cell responses, and protected against EHEC O157:H7 colonization and infection in mice [136].

This review gave you knowledge to understand the immune system and recent developments in cloning and expression techniques as demonstrating and support the concern of using Lactobacillus strains, to develop novel therapeutic protein mucosal delivery vectors which should be tested now in human clinical trials.

\section{Safety Concerns of Lactobacillus Strains}

Our study was confirmed that there were no significant adverse events have been demonstrated in the experimental, clinical studies and other controlled trials of Lactobacillus species strains because are not expected to degrade host tissue components for example Lactobacillus rhamnosus GG; it has been administered to children with chronic inflammatory disease, to adults with inflammatory bo- 
wel disease, and to patients with HIV. The administration of Lactobacillus johnsonii N6.2 did not modify the Comprehensive metabolic panel (CMP) or complete blood count $(\mathrm{CBC})$ of participants this also important common safety [112]. Combinations of Lactobacillus rhamnosus or Lactobacillus paracasei with Bifidobacterium longum has been used safely from 2 months before delivery until the breastfed infant was 2 months and study of Lactobacillus Fermentum CECT5716 as prevention of mastitis in breastfeeding women [138] [139]. It is safe when taken by mouth appropriately many studies were orally administered; Lactobacillus is also likely safe for women to use inside the vagina [122]. To prevent the reproduction of Lactobacillus species in the environment recombinant plasmids and chromosomally-modified bacterial strains can be controlled by the use of auxotrophic mutants. Lactobacillus has rarely caused disease in people with weakened immune systems and side effects are usually mild and mainly frequently include intestinal gas.

For these reasons, Lactobacillus species has been proven safe both invitro and invivo and are considered as suitable mucosal delivery vectors for heterologous antigens and can be used in clinical trials.

\section{Discussion}

Lactobacillus strains as probiotic activate the mucosal immune system through the stimulation of gut antigen presenting cells to promote protection. Different probiotic strains of Lactobacillus genera acquire significant and widely acknowledged immunomodulatory properties and health-promoting [35] [140]. The approaches leading to the efficient targetness engages the natural ways which do not cause any side effects and assist the body to uphold the immune homeostasis such as the use of probiotics are the ways forward. Different studies have looked into the prospective mechanisms of action by which Lactobacillus strains as probiotics might play a role as primary immune response against pathogens.

More recent studies developed a recombinant Lactobacillus strains harbouring proteins or antigens in order to control infections [30] [32] [34] [35] [40] [125] [126]. Lactobacillus species based vaccines can regulate immunostimulatory responses and make active antigen presenting cells (APCs), such as macrophages T cells, dendritic cells (DCs) and epithelial cells. DCs are seen as professional APCs that elicit a primary immune response against pathogens challenge [80]. However, several current studies have point out that immunostimulatory function showed tissue-specific differences among DCs in terms of inducing T helper (Th) cell responses [35] [130] [131] [132] and recommended that Lactobacillus species are actively concerned in the improvement of adaptive immune responses by programming many aspects of CD4+ T cell differentiation [80]. In additional many Lactobacillus species are microbe-associated molecular pattern (MAMPs) is capable of interacting with epithelial pattern recognition receptors, mainly the Toll-like receptor-2 (TLR2), TLR6 and nod-like receptors which 
leads to an up-regulation of signaling pathways to modulate the host's immune response [141] [142].

In recent years, studies using newly developed technology and analytic methods suggests that Lactobacillus species may enhance host defenses and improve vaccine response as a result of the influence of bacteria on host immunity and intestinal integrity against enteric parasites and that Lactobacillus strains as probiotics have been extensively studied as a treatment option of various diseases such as: Viral infections in animals and humans, probiotics modulate mucosal immunity, reduced rotavirus binding and infection, and produced antimicrobial peptides with anti-viral activity against rotavirus [33] [143] [144], cancer [106] [145] [146], Haemorrhagic cecal Coccidiosis [124], Hypertension [69], obesity [147], diabetes [148], human immunodeficiency virus infection [20], Irritable bowel syndrome [44], fish and shellfish species diseases [149], Fungal infections [150], vaginal health [151].

The administration of microbial metabolites for the prevention and treatment of aberrant immune response is also gaining importance [106] [152]. The market size of probiotics has to the highest degree increased consumer anxiety concerning health-promoting effect of nutraceuticals [38] [140] [153].

Researchers have discovered more specific functions of Lactobacillus species in mediating host immunity and immunologic diseases, such as have been revealed to directly down regulate $\mathrm{T}$ effector-mediated inflammatory responses as upregulating anti-inflammatory $\mathrm{T}$ regulatory cell expression in mice [45] [93]. Similarly Wang and colleagues found that, pretreatment with Lactobacillus plantarum L9 to prevent tumour necrosis factor (TNF- $\alpha$ ) induced transcellular bacterial translocation and IL-8 production in Caco-2 cells, the researcher demonstrated that it showed the potential to protect enterocytes from an acute inflammatory response and concluded as good potential prophylactic agents in counteracting bacterial translocation, as well in the mixed Lactobacillus plantarum group IFN-/IL-4 decreased significantly from infection to convalescence but there was significantly higher secretion of sIgA in the intestine of mice [91].

Wen and colleagues' 2015 study of Lactobacillus GG (LGG) when supplemented in gnotobiotic pigs, with an oral attenuated human rhinovirus(HRV) vaccine found significant strong adjuvant effect and increased mucosal populations of HRV-specific IFN-gamma producing T lymphocytes and oral administration of LGG attenuates an $S$. Infantis-induced increase in the level of serum IL-22, excessive Th1 immune responses and induces the expansion of $\mathrm{CD} 4^{+} \mathrm{T}-$ bet ${ }^{+} \mathrm{IFN} \gamma^{+} \mathrm{T}$ cells in peripheral blood, which helps in the eradication of intracellular pathogens [134].

The current studies by Rocha-Ramirez and colleagues' 2017 and 2016 found that nuclear translocation NF- $\mathrm{kB}$ pp65 and TLR2-dependent signaling were increased by treatment with the Lactobacillus species ( $L$. rhamnosus GG, L. rhamnosus KLSD, L. helveticus IMAU70129, and L. casei IMAU60214). This demonstrates that probiotic strains of Lactobacillus exert early immunostimula- 
tory effects that may be directly linked to the initial inflammation of the response of human macrophages [98] [154]. Lactobacillus species such as Lactobacillus plantarum, and Lactobacillu scasei have been shown to increase the expression of proteins involved in tight junction barrier function which induces several protective mechanisms that restore tissue damage, such as modulation of the stability of tight junctions of the gastrointestinal lining because when become compromised and permeability increases, it allows toxins and other forms of waste to leak into the bloodstream then endotoxins trigger immune activation through Toll-like receptor 4 (TLR4) [94] [155].

Live Lactobacillus rhamnosus $G G$ and UV-inactivated showed that are equally effective in decreasing IL-8 in the intestinal epithelium [98]. Live and heat-killed Lactobacillus rhamnosus $G G$ confirmed that are competent to exert comparable effects on the secretion of pro- and anti-inflammatory cytokines and chemokines when included in the diet of infant rats and have reported that these bacteria had an impact on the phagocytic activity of macrophages against extracellular pathogens such as Lactobacillus acidophilus ADDIN EN.CITE [156].

Recently, Albarracin, Clua, Kolling, Zelayaand colleagues took a different approach studies about Lactobacillus rhamnosus and found that induces cytokines which are involved in the immunomodulatory protective effect of HK1505 and PG1505 in the respiratory superinfection: IL-10, IFN- $\beta$, and IFN- $\gamma$, pointed out that IL-10 involved in the protection against inflammatory damage, while IFN- $\gamma$ participated in the reduction of pneumococcal growth in the lungs. As well $L$. rhamnosus CRL1505 improved the numbers of $\mathrm{CD}^{+} \mathrm{CD} 4^{+} \mathrm{IFN}-\gamma^{+}$, and $\mathrm{CD}^{+} \mathrm{CD}^{+} \mathrm{IL}_{-}-10^{+} \mathrm{T}$ cells in the lungs of infant mice and IFN- $\beta$ involved in the protection against lung tissue injury [75] [157] [158] [159].

Studies by Ren, wan, Kemgang, Jung and colleagues found that Lactobacillus strains induces Th1 mediates cellular immunity and secretion of IFN- $\gamma$ cytokines, a Th2 response to humoral immunity, and IL-4 secretion which are able to capture intracellular bacteria, viruses, and cancer. Lactobacillus strains increase Th1 type IFN- $\gamma$ cytokine secretion in spleen cells of mice infected with $S$. aureus while reducing the secretion of Th2 type IL- 4 cytokines, also revealed that, serum IFN- $\gamma$ levels were higher in the mice infected with Lactobacillus strains compared to mice infected with the control. Some studies have shown that IL-4 is the key to the survival and proliferation of T cells, as IL-4 promotes the production of Th2 cells and excessive IL- 4 inhibits the production of IFN- $\gamma$. The level of sIgA which inhibits allergenic and pathogenic microorganisms in the intestinal contents of mice treated with Lactobacillus strains were significantly higher [45] [160] [161] [162].

Lactobacillus strains have reported to activate Toll-like receptors (TLR) signaling which induces an increase in the production of proinflammatory cytokines for instance TNF- $\alpha$, IL-12, and IL- 8 which damage the host beyond the defense against invading pathogens, also increases in the secretion of anti-inflammatory cytokines such as IL-10.Lactobacillus strains probiotics and 
several TLR antagonists have revealed constructive results in the treatment of obesity and other related diseases including diabetes mellitus. [57] [64] [163].

It was also shown that mixed Lactobacillus plantarum used as inhibition of Staphylococcus aureus by crude and fractionated extract from lactic acid bacteria IFN- $\gamma /$ IL-4 ratio decreased appreciably from infection to recovery. The secretion of sIgA in the intestine of mice was significantly higher in the mixed Lactobacillus plantarum group than in the single lactic acid bacteria group. Treatment with mixed Lactobacillus strains increased the anti-inflammatory factor and the secretion of sIgA in the intestine of mice infected with Staphylococcus aureus and inhibited inflammation [45] [133]. Evaluation of Lactobacillus coryniformis CECT5711 strain as a coadjuvant in a vaccination process [16].

Lactobacillus rhamnosus JB-1 strain modulates goblet cell biology and endorses parasite removal via an IL-10-mediated pathway and gives narrative approaching into probiotic effects on innate defense in nematode infection [52]. It was suggested that Lactobacillus reuteri as a functional probiotic against food allergy in allergic mice there were production of serum IgE, activation of mast cell, signature T helper (Th) 1 and 2 cytokines; IFN-c and IL-4. Further it was made known that the intestinal expression of IL-4, IFN-c, GATA3 and T-bet was down-regulated, improved the expression of IL-10, TGF-b and Foxp3, and the number of IL-10-secreting CD11c+CD103+ mesenteric lymph node (MLN) cells and heat killed Lactobacillus reuteri attenuated OVA-induced cell proliferation and IL-2 secretion by MLN cells [123]. Also Lactobacillus strains can improve health in the course of many mechanisms/means, to protect the host against potentially pathogenic species that populate the GIT of animals and humans. Lactobacilli strains, such as Lactobacillus acidophilus LA1, are able to prevent the colonization of the intestine by pathogenic bacteria, such as Salmonella typhimurium, Staphylococcus aureus, and Pseudomonas aeruginosa, by antagonistic elimination. Lactobacillus strains may protect the host from pathogen invasion by increasing the intestinal epithelial barrier. Some LAB microbe-associated molecular patterns (MAMPs) are able of working together with the Toll-like receptor-2 (TLR2), TLR6 and nod-like receptors [94]. Moreover Lactobacillus salivarius JTB07 and Lactobacillus reuteri JTB07 have been reported to upregulate the expression of IL-12, IL-8, IL-6, and IL-1, while Lactobacillus acidophilus JTB05 to upregulate the interferon-gamma expression level of their host cells [45] [159] [164]. Lactobacillus salivarius UCC 118 and Lactobacillus johnsonii LJ-1 were reported to enhance the IgA response and phagocytic activity in head-kidney leucocytes [165].

Many of published research reports have indicated the significance of producing interferon-gamma (IFN- $\gamma$ ), interleukin as well as IgA for treatment of diseases because were repeatedly observed. Development of immunity by Lactobacillus strains could associated with lymphoid tissues that regulate the immune response of their hosts for example Lactobacillus helveticus R389, Lactobacillus rhamnosus HN001 and Lactobacillus acidophilus HN017 [97] [166] [167] [168] 
have been reported to have the ability to improve the immune system of their host. The mechanism of this improvement is thought to be caused by the consequence of the Lactobacillus strains because of the: total serum protein, globulin, interferon-gamma, prostaglandin E production, albumin, tumor necrosis factor, interleukin-1 (IL-1), interleukin-2 (IL-2), interleukin-4 (IL-4), interleukin-6 (IL-6), and lymphocytes proliferation.

\section{Conclusion and Recommendation}

This review has tried to study experimental and clinical studies that are providing a clear understanding of the beneficial Lactobacillus strains which have been applied from the year 2015 to 2017. Collectively, the review results support Lactobacillus species as probiotics because various Lactobacillus strains have proved to be effective and powerful tools for use in human and animal health as antimicrobial against a wide range of potential pathogens and management of metabolic disorders, Vectors expression systems, and immunization strategies have gradually increased the potential use of Lactobacillus strains. For this reason, Lactobacillus species are considered as a potential replacement of traditional, frequently pathogenic, attenuated microbial transporters. A favorable point of using Lactobacillus strains probiotics is the ability to use the mucosal administration, particularly via the universal oral route, which presents several advantages: simplifies vaccine administration, promotes a special type of local immunity and is attractive from the immunological and practical approach, especially for mass vaccination programs in contrast to systemic inoculation. This review sum up and sort out the available information on the application of Lactobacillus species as live oral vaccine vectors for induction of immune responses and treatment of pathogenic and metabolic diseases. It constitutes an important source of general information for researchers interested in mucosal vaccine development and constructing Lactobacillus strains with vaccine potential. About the safety of Lactobacillus strains, the combining of the high immunogenicity vectors with low risk is a proper level of safety, efficacy and providing proper biological control of the recombinant microorganism. Therefore Lactobacillus strains can be considered as good candidates for diseases treatment and vaccine development as heterologous protein secretion to date.

\section{Acknowledgements}

The financial support by Chinese Government through a grant from the Chinese Government (CSC) (Grant number 201508330278) is highly acknowledged. Also we are thankful to the Jilin Agricultural University for the internet to download Data for this review.

\section{Funding}

This study was funded by Chinese Government (CSC) Grant number 201508330278. 


\section{Availability of Data and Materials}

Not applicable.

\section{Conflict of Interest}

Author1 declares that she has no conflict of interest.

Author 2 declares that he has no conflict of interest.

Author 3 declares that she has no conflict of interest.

Author 4 declares that she has no conflict of interest.

Author 5 declares that she has no conflict of interest.

\section{Consent for Publication}

Not applicable.

\section{Ethical Approval}

This article does not contain any studies with human participants or animals performed by any of the authors."

\section{Authors' Contributions}

Author 1 searching data and writing first draft.

Author 2 writing second draft.

Author 3 references writing.

Author 4 and Author 5 Supervisions and editing last draft of the manuscript.

"All authors read and approved the final version of the manuscript".

\section{References}

[1] Robert, L. and Labat-Robert, J. (2017) Comments on the History of Medical-Biological Studies of Aging, the Birth of Scientific Gerontology. Current Research in Translational Medicine, 65, 44-47.

[2] Nguyen, T.T., Nguyen, H.M., Geiger, B., Mathiesen, G., Eijsink, V.G., Peterbauer, C.K., Haltrich, D. and Nguyen, T.H. (2015) Heterologous Expression of a Recombinant Lactobacillal Beta-Galactosidase in Lactobacillus Plantarum: Effect of Different Parameters on the Sakacin P-Based Expression System. Microbial Cell Factories, 14, 30. https://doi.org/10.1186/s12934-015-0214-8

[3] Bothe, M.K., Maathuis, A.J.H., Bellmann, S., van der Vossen, J., Berressem, D., Koehler, A., Schwejda-Guettes, S., Gaigg, B., Kuchinka-Koch, A. and Stover, J.F. (2017) Dose-Dependent Prebiotic Effect of Lactulose in a Computer-Controlled In Vitro Model of the Human Large Intestine. Nutrients, 9. https://doi.org/10.3390/nu9070767

[4] Sugahara, H., Yao, R., Odamaki, T. and Xiao, J.Z. (2017) Differences between Live and Heat-Killed Bifidobacteria in the Regulation of Immune Function and the Intestinal Environment. Beneficial Microbes, 8, 463-472. https://doi.org/10.3920/BM2016.0158

[5] Szatraj, K., Szczepankowska, A.K. and Chmielewska-Jeznach, M. (2017) Lactic Acid Bacteria-Promising Vaccine Vectors: Possibilities, Limitations, Doubts. Journal of Applied Microbiology, 123, 325-339. https://doi.org/10.1111/jam.13446 
[6] Linares, D.M., Gomez, C., Renes, E., Fresno, J.M., Tornadijo, M.E., Ross, R.P. and Stanton, C. (2017) Lactic Acid Bacteria and Bifidobacteria with Potential to Design Natural Biofunctional Health-Promoting Dairy Foods. Frontiers in Microbiology, 8, 846. https://doi.org/10.3389/fmicb.2017.00846

[7] Melo, T.A., Dos Santos, T.F., Pereira, L.R., Passos, H.M., Rezende, R.P. and Romano, C.C. (2017) Functional Profile Evaluation of Lactobacillus Fermentum TCUESC01: A New Potential Probiotic Strain Isolated during Cocoa Fermentation. BioMed Research International, 2017, 5165916.

[8] Odamaki, T., Kato, K., Sugahara, H., Xiao, J.Z., Abe, F. and Benno, Y. (2016) Effect of Probiotic Yoghurt on Animal-Based Diet-Induced Change in Gut Microbiota: An Open, Randomised, Parallel-Group Study. Beneficial Microbes, 7, 473-484.

https://doi.org/10.3920/BM2015.0173

[9] Nuraida, L. (2015) A Review: Health Promoting Lactic Acid Bacteria in Traditional Indonesian Fermented Foods. Food Science and Human Wellness, 4, 47-55. https://doi.org/10.1016/j.fshw.2015.06.001

[10] Hadaegh, H., Seyyedain Ardabili, S.M., Tajabadi Ebrahimi, M., Chamani, M. and Azizi Nezhad, R. (2017) The Impact of Different Lactic Acid Bacteria Sourdoughs on the Quality Characteristics of Toast Bread. Journal of Food Quality, 2017, 1-11.

[11] Reale, A., Di Renzo, T., Zotta, T., Preziuso, M., Boscaino, F., Ianniello, R., Storti, L.V., Tremonte, P. and Coppola, R. (2016) Effect of Respirative Cultures of Lactobacillus casei on Model Sourdough Fermentation. LWT - Food Science and Technology, 73, 622-629. https://doi.org/10.1016/j.lwt.2016.06.065

[12] Garcia-Mantrana, I., Yebra, M.J., Haros, M. and Monedero, V. (2016) Expression of Bifidobacterial Phytases in Lactobacillus casei and Their Application in a Food Model of Whole-Grain Sourdough Bread. International Journal of Food Microbiology, 216, 18-24. https://doi.org/10.1016/j.ijfoodmicro.2015.09.003

[13] Ventimiglia, G., Alfonzo, A., Galluzzo, P., Corona, O., Francesca, N., Caracappa, S., Moschetti, G. and Settanni, L. (2015) Codominance of Lactobacillus plantarum and Obligate Heterofermentative Lactic Acid Bacteria during Sourdough Fermentation. Food Microbiology, 51, 57-68. https://doi.org/10.1016/j.fm.2015.04.011

[14] Lee, A., Lee, Y.J., Yoo, H.J., Kim, M., Chang, Y., Lee, D.S. and Lee, J.H. (2017) Consumption of Dairy Yogurt Containing Lactobacillus paracasei ssp. Paracasei, Bifidobacterium animalis ssp. Lactis and Heat-Treated Lactobacillus plantarum Improves Immune Function Including Natural Killer Cell Activity. Nutrients, 9. https://doi.org/10.3390/nu9060558

[15] Min, M., Bunt, C.R., Mason, S.L., Bennett, G.N. and Hussain, M.A. (2017) Effect of Non-Dairy Food Matrices on the Survival of Probiotic Bacteria during Storage. Microorganisms, 5.

[16] Redondo, N., Nova, E., Gheorghe, A., Diaz, L.E., Hernandez, A. and Marcos, A. (2017) Evaluation of Lactobacillus coryniformis CECT5711 Strain as a Coadjuvant in a Vaccination Process: A Randomised Clinical Trial in Healthy Adults. Nutrition \& Metabolism, 14, 2. https://doi.org/10.1186/s12986-016-0154-2

[17] Nishida, S., Ishii, M., Nishiyama, Y., Abe, S., Ono, Y. and Sekimizu, K. (2017) Lactobacillus paraplantarum 11-1 Isolated from Rice Bran Pickles Activated Innate Immunity and Improved Survival in a Silkworm Bacterial Infection Model. Frontiers in Microbiology, 8.

[18] Singh, R.K., Chang, H.W., Yan, D., Lee, K.M., Ucmak, D., Wong, K., Abrouk, M., Farahnik, B., Nakamura, M., Zhu, T.H., et al. (2017) Influence of Diet on the Gut microbiome and Implications for Human Health. Journal of Translational Medi- 
cine, 15,73 .

[19] Lim, F., Lim, S. and Ramasamy, K. (2017) Pediococcus Acidilactici LAB4 and Lactobacillus plantarum LAB12 Assimilate Cholesterol and Modulate ABCA1, CD36, NPC1L1 and SCARB1 in Vitro. Beneficial Microbes, 8, 97-109. https://doi.org/10.3920/BM2016.0048

[20] Lee, S., You, H.J., Kwon, B. and Ko, G. (2017) Complete Genome Sequence of Lactobacillus jensenii Strain SNUV360, a Probiotic for Treatment of Bacterial Vaginosis Isolated from the Vagina of a Healthy Korean Woman. Genome Announcements, 5. https://doi.org/10.1128/genomeA.01757-16

[21] Biagioli, M., Laghi, L., Carino, A., Cipriani, S., Distrutti, E., Marchiano, S., Parolin, C., Scarpelli, P., Vitali, B. and Fiorucci, S. (2017) Metabolic Variability of a Multispecies Probiotic Preparation Impacts on the Anti-Inflammatory Activity. Frontiers in Pharmacology, 8, 505. https://doi.org/10.3389/fphar.2017.00505

[22] Toshimitsu, T., Ozaki, S., Mochizuki, J., Furuichi, K. and Asami, Y. (2017) Effects of Lactobacillus plantarum Strain OLL2712 Culture Conditions on the Anti-Inflammatory Activities for Murine Immune Cells and Obese and Type 2 Diabetic Mice. Applied and Environmental Microbiology, 83.

https://doi.org/10.1128/AEM.03001-16

[23] Saez-Lara, M.J., Gomez-Llorente, C., Plaza-Diaz, J. and Gil, A. (2015) The Role of Probiotic Lactic Acid Bacteria and Bifidobacteria in the Prevention and Treatment of Inflammatory Bowel Disease and Other Related Diseases: A Systematic Review of Randomized Human Clinical Trials. BioMed research international, 2015, 505878.

[24] Fonseca, W., Lucey, K., Jang, S., Fujimura, K.E., Rasky, A., Ting, H.A., Petersen, J., Johnson, C.C., Boushey, H.A., Zoratti, E., et al. (2017) Lactobacillus johnsonii Supplementation Attenuates Respiratory Viral Infection via Metabolic Reprogramming and Immune Cell Modulation. Mucosal Immunology.

https://doi.org/10.1038/mi.2017.13

[25] Bharwani, A., Mian, M.F., Surette, M.G., Bienenstock, J. and Forsythe, P. (2017) Oral Treatment with Lactobacillus rhamnosus Attenuates Behavioural Deficits and Immune Changes in Chronic Social Stress. BMC Medicine, 15, 7. https://doi.org/10.1186/s12916-016-0771-7

[26] Wang, H., Lee, I.-S., Braun, C. and Enck, P. (2016) Effect of Probiotics on Central Nervous System Functions in Animals and Humans: A Systematic Review. Journal of Neurogastroenterology and Motility, 22, 589. https://doi.org/10.5056/jnm16018

[27] Gordon, M., Wallace, C., Stone, J., Thomas, A. and Akobeng, A. (2016) G38(P) Probiotics for Treatment of Chronic Constipation in Children: A Cochrane Systematic Review. Archives of Disease in Childhood, 101, A25.

[28] Gibson, G.R., Hutkins, R., Sanders, M.E., Prescott, S.L., Reimer, R.A., Salminen, S.J., Scott, K., Stanton, C., Swanson, K.S., Cani, P.D., et al. (2017) Expert Consensus Document: The International Scientific Association for Probiotics and Prebiotics (ISAPP) Consensus Statement on the Definition and Scope of Prebiotics. Nature Reviews Gastroenterology \& Hepatology, 14, 491-502. https://doi.org/10.1038/nrgastro.2017.75

[29] Yang, W.T., Yang, G.L., Wang, Q., Huang, H.B., Jiang, Y.L., Shi, C.W., Wang, J.Z., Huang, K.Y., Jin, Y.B. and Wang, C.F. (2017) Protective Efficacy of Fc Targeting Conserved Influenza Virus M2e Antigen Expressed by Lactobacillus plantarum. Antiviral Research, 138, 9-21. https://doi.org/10.1016/j.antiviral.2016.11.025

[30] Yang, G., Jiang, Y., Tong, P., Li, C., Yang, W., Hu, J., Ye, L., Gu, W., Shi, C., Shan, B., et al. (2017) Alleviation of Enterotoxigenic Escherichia Coli Challenge by Re- 
combinant Lactobacillus plantarum Expressing a FaeG- and DC-Targeting Peptide Fusion Protein. Beneficial Microbes, 8, 379-391.

https://doi.org/10.3920/BM2016.0116

[31] Jiang, Y., Yang, G., Wang, Q., Wang, Z., Yang, W., Gu, W., Shi, C., Wang, J., Huang, H. and Wang, C. (2017) Molecular Mechanisms Underlying Protection against H9N2 Influenza Virus Challenge in Mice by Recombinant Lactobacillus plantarum with Surface Displayed HA2-LTB. Journal of Biotechnology, 259, 6-14. https://doi.org/10.1016/j.jbiotec.2017.08.011

[32] Liu, Y.Y., Yang, W.T., Shi, S.H., Li, Y.J., Zhao, L., Shi, C.W., Zhou, F.Y., Jiang, Y.L., $\mathrm{Hu}$, J.T., Gu, W., et al. (2017) Immunogenicity of Recombinant Lactobacillus plantarum NC8 Expressing Goose Parvovirus VP2 Gene in BALB/c Mice. Journal of Veterinary Science, 18, 159-167. https://doi.org/10.4142/jvs.2017.18.2.159

[33] Wang, Y.B., Du, W., Fu, A.K., Zhang, X.P., Huang, Y., Lee, K.H., Yu, K., Li, W.F. and Li, Y.L. (2016) Intestinal Microbiota and Oral Administration of Enterococcus faecium Associated with the Growth Performance of New-Born Piglets. Beneficial Microbes, 7, 529-538. https://doi.org/10.3920/BM2015.0099

[34] Shi, S.H., Yang, W.T., Yang, G.L., Zhang, X.K., Liu, Y.Y., Zhang, L.J., Ye, L.P., Hu, J.T., Xing, X., Qi, C., et al. (2016) Lactobacillus plantarum Vaccine Vector Expressing Hemagglutinin Provides Protection against H9N2 Challenge Infection. Virus Research, 211, 46-57. https://doi.org/10.1016/j.virusres.2015.09.005

[35] Cai, R., Jiang, Y., Yang, W., Yang, W., Shi, S., Shi, C., Hu, J., Gu, W., Ye, L., Zhou, F., et al. (2016) Surface-Displayed IL-10 by Recombinant Lactobacillus plantarum Reduces Th1 Responses of RAW264.7 Cells Stimulated with Poly(I:C) or LPS. Journal of Microbiology and Biotechnology, 26, 421-431. https://doi.org/10.4014/jmb.1509.09030

[36] Allain, T., Mansour, N.M., Bahr, M.M.A., Martin, R., Florent, I., Langella, P. and Bermúdez-Humarán, L.G. (2016) A New Lactobacilli In Vivo Expression System for the Production and Delivery of Heterologous Proteins at Mucosal Surfaces. FEMS Microbiology Letters, 363, fnw117-fnw117.

[37] Suryavanshi, M.V., Paul, D., Doijad, S.P., Bhute, S.S., Hingamire, T.B., Gune, R.P. and Shouche, Y.S. (2017) Draft Genome Sequence of Lactobacillus plantarum Strains E2C2 and E2C5 Isolated from Human Stool Culture. Standards in Genomic Sciences, 12, 15. https://doi.org/10.1186/s40793-017-0222-x

[38] Evivie, S.E., Huo, G.C., Igene, J.O. and Bian, X. (2017) Some Current Applications, Limitations and Future Perspectives of Lactic Acid Bacteria as Probiotics. Food \& Nutrition Research, 61, 1318034. https://doi.org/10.1080/16546628.2017.1318034

[39] Wells, J.M. (2011) Immunomodulatory Mechanisms of Lactobacilli. Microbial Cell Factories, 10, S17. https://doi.org/10.1186/1475-2859-10-S1-S17

[40] Drouault, S., Juste, C., Marteau, P., Renault, P. and Corthier, G. (2002) Oral Treatment with Lactococcus lactis Expressing Staphylococcus hyicus Lipase Enhances Lipid Digestion in Pigs with Induced Pancreatic Insufficiency. Applied and Environmental Microbiology, 68, 3166-3168. https://doi.org/10.1128/AEM.68.6.3166-3168.2002

[41] Kang, J., Chung, W.H., Lim, T.J., Whon, T.W., Lim, S. and Nam, Y.D. (2017) Complete Genome Sequence of Lactobacillus casei LC5, a Potential Probiotics for Atopic Dermatitis. Frontiers in Immunology, 8, 413. https://doi.org/10.3389/fimmu.2017.00413

[42] Kazou, M., Alexandraki, V., Pot, B., Tsakalidou, E. and Papadimitriou, K. (2017) Complete Genome Sequence of the Dairy Isolate Lactobacillus acidipiscis ACA-DC 
1533. Genome Announcements, 5. https://doi.org/10.1128/genomeA.01533-16

[43] Pan, L., Zhao, P.F., Ma, X.K., Shang, Q.H., Xu, Y.T., Long, S.F., Wu, Y., Yuan, F.M. and Piao, X.S. (2017) Probiotic Supplementation Protects Weaned Pigs against Enterotoxigenic Escherichia coli K88 Challenge and Improves Performance Similar to Antibiotics. Journal of Animal Science, 95, 2627-2639. https://doi.org/10.2527/jas.2016.1243

[44] Wang, M., Gao, Z., Zhang, Y. and Pan, L. (2016) Lactic Acid Bacteria as Mucosal Delivery Vehicles: A Realistic Therapeutic Option. Applied Microbiology and Biotechnology, 100, 5691-5701. https://doi.org/10.1007/s00253-016-7557-x

[45] Ren, D., Gong, S., Shu, J., Zhu, J., Rong, F., Zhang, Z., Wang, D., Gao, L., Qu, T., Liu, H., et al. (2017) Mixed Lactobacillus plantarum Strains Inhibit Staphylococcus aureus Induced Inflammation and Ameliorate Intestinal Microflora in Mice. BioMed Research International, 2017, Article ID: 7476467.

[46] Oldak, A. and Zielinska, D. (2017) Comparison of Antibacterial Activity of Lactobacillus plantarum Strains Isolated from Two Different Kinds of Regional Cheeses from Poland: Oscypek and Korycinski Cheese. BioMed Research International, 2017, Article ID: 6820369.

[47] Carvalho, R.D., Breyner, N., Menezes-Garcia, Z., Rodrigues, N.M., Lemos, L., Maioli, T.U., da Gloria Souza, D., Carmona, D., de Faria, A.M., Langella, P., et al. (2017) Secretion of Biologically Active Pancreatitis-Associated Protein I (PAP) by Genetically Modified Dairy Lactococcus lactis NZ9000 in the Prevention of Intestinal Mucositis. Microbial Cell Factories, 16, 27. https://doi.org/10.1186/s12934-017-0624-x

[48] Sebastian Domingo, J.J. (2017) Review of the Role of Probiotics in Gastrointestinal Diseases in Adults. Gastroenterologia y Hepatologia, 40, 417-429.

[49] Chang, C. and Lin, H. (2016) Dysbiosis in Gastrointestinal Disorders. Best Practice \& Research Clinical Gastroenterology, 30, 3-15. https://doi.org/10.1016/j.bpg.2016.02.001

[50] Antunes, M.M., Leocadio, P.C., Teixeira, L.G., Leonel, A.J., Cara, D.C., Menezes, G.B., Generoso, S.deV., Cardoso, V.N., Alvarez-Leite, J.I. and Correia, M.I. (2016) Pretreatment With L-Citrulline Positively Affects the Mucosal Architecture and Permeability of the Small Intestine in a Murine Mucositis Model. JPEN Journal of Parenteral and Enteral Nutrition, 40, 279-286.

https://doi.org/10.1177/0148607114567508

[51] Benbouziane, B., Ribelles, P., Aubry, C., Martin, R., Kharrat, P., Riazi, A., Langella, P. and Bermudez-Humaran, L.G. (2013) Development of a Stress-Inducible Controlled Expression (SICE) System in Lactococcus lactis for the Production and Delivery of Therapeutic Molecules at Mucosal Surfaces. Journal of Biotechnology, 168, 120-129. https://doi.org/10.1016/j.jbiotec.2013.04.019

[52] Zanni, E., Schifano, E., Motta, S., Sciubba, F., Palleschi, C., Mauri, P., Perozzi, G., Uccelletti, D., Devirgiliis, C. and Miccheli, A. (2017) Combination of Metabolomic and Proteomic Analysis Revealed Different Features among Lactobacillus delbrueckii Subspecies Bulgaricus and Lactis Strains While In Vivo Testing in the Model Organism Caenorhabditis elegans Highlighted Probiotic Properties. Frontiers in Microbiology, 8, 1206. https://doi.org/10.3389/fmicb.2017.01206

[53] Villena, J., Vizoso-Pinto, M.G. and Kitazawa, H. (2016) Intestinal Innate Antiviral Immunity and Immunobiotics: Beneficial Effects against Rotavirus Infection. Frontiers in Immunology, 7, 563. https://doi.org/10.3389/fimmu.2016.00563

[54] Chenoll, E., Casinos, B., Bataller, E., Buesa, J., Ramon, D., Genoves, S., Fabrega, J., 
Rivero Urgell, M. and Moreno Munoz, J.A. (2016) Identification of a Peptide Produced by Bifidobacterium longum CECT 7210 with Antirotaviral Activity. Frontiers in Microbiology, 7, 655. https://doi.org/10.3389/fmicb.2016.00655

[55] Vlasova, A.N., Kandasamy, S., Chattha, K.S., Rajashekara, G. and Saif, L.J. (2016) Comparison of Probiotic Lactobacilli and Bifidobacteria Effects, Immune Responses and Rotavirus Vaccines and Infection in Different Host Species. Veterinary Immunology and Immunopathology, 172, 72-84.

https://doi.org/10.1016/j.vetimm.2016.01.003

[56] Liu, H., Hou, C., Wang, G., Jia, H., Yu, H., Zeng, X., Thacker, P.A., Zhang, G. and Qiao, S. (2017) Lactobacillus reuteri 5007 Modulates Intestinal Host Defense Peptide Expression in the Model of IPEC-J2 Cells and Neonatal Piglets. Nutrients, 9. https://doi.org/10.3390/nu9060559

[57] Olek, A., Woynarowski, M., Ahren, I.L., Kierkus, J., Socha, P., Larsson, N. and Onning, G. (2017) Efficacy and Safety of Lactobacillus plantarum DSM 9843 (LP299V) in the Prevention of Antibiotic-Associated Gastrointestinal Symptoms in Children-Randomized, Double-Blind, Placebo-Controlled Study. The Journal of Pediatrics, 186, 82-86. https://doi.org/10.1016/j.jpeds.2017.03.047

[58] Awaad, A.S., Al-Mudhayyif, H.A., Al-Othman, M.R., Zain, M.E. and El-Meligy, R.M. (2017) Amhezole, a Novel Fungal Secondary Metabolite from Aspergillus terreus for Treatment of Microbial Mouth Infection. Phytotherapy Research: PTR, 31, 395-402.

[59] Park, M.S., Kwon, B., Ku, S. and Ji, G.E. (2017) The Efficacy of Bifidobacterium longum BORI and Lactobacillus acidophilus AD031 Probiotic Treatment in Infants with Rotavirus Infection. Nutrients, 9. https://doi.org/10.3390/nu9080887

[60] Bereswill, S., Ekmekciu, I., Escher, U., Fiebiger, U., Stingl, K. and Heimesaat, M.M. (2017) Lactobacillus johnsonii Ameliorates Intestinal, Extra-Intestinal and Systemic Pro-Inflammatory Immune Responses Following Murine Campylobacter jejuni Infection. Scientific Reports, 7, 2138. https://doi.org/10.1038/s41598-017-02436-2

[61] Ballal, S.A., Veiga, P., Fenn, K., Michaud, M., Kim, J.H., Gallini, C.A., Glickman, J.N., Quere, G., Garault, P., Beal, C., et al. (2015) Host Lysozyme-Mediated Lysis of Lactococcus lactis Facilitates Delivery of Colitis-Attenuating Superoxide Dismutase to Inflamed Colons. Proceedings of the National Academy of Sciences of the United States of America, 112, 7803-7808. https://doi.org/10.1073/pnas.1501897112

[62] Leal, J.R., Heitman, S.J., Conly, J.M., Henderson, E.A. and Manns, B.J. (2016) Cost-Effectiveness Analysis of the Use of Probiotics for the Prevention of Clostridium Difficile-Associated Diarrhea in a Provincial Healthcare System. Infection Control and Hospital Epidemiology, 37, 1079-1086.

https://doi.org/10.1017/ice.2016.134

[63] Golic, N., Veljovic, K., Popovic, N., Djokic, J., Strahinic, I., Mrvaljevic, I. and Terzic-Vidojevic, A. (2017) In Vitro and In Vivo Antagonistic Activity of New Probiotic Culture against Clostridium Difficile and Clostridium perfringens. BMC Microbiology, 17, 108. https://doi.org/10.1186/s12866-017-1015-5

[64] Mallina, R., Craik, J., Briffa, N., Ahluwalia, V., Clarke, J. and Cobb, A.G. (2017) Probiotic Containing Lactobacillus casei, Lactobacillus bulgaricus, and Streptococcus thermophiles (ACTIMEL) for the Prevention of Clostridium difficile Associated Diarrhoea in the Elderly with Proximal Femur Fractures. Journal of Infection and Public Health. https://doi.org/10.1016/j.jiph.2017.04.001

[65] Rodrigues, F., Iturriza-Gómara, M., Marlow, R., Gray, J., Nawaz, S., Januário, L. and Finn, A. (2013) The Evolving Epidemiology of Rotavirus Gastroenteritis in Central 
Portugal with Modest Vaccine Coverage. Journal of Clinical Virology, 56, 129-134. https://doi.org/10.1016/j.jcv.2012.10.016

[66] Fernandez, M.A. and Marette, A. (2017) Potential Health Benefits of Combining Yogurt and Fruits Based on Their Probiotic and Prebiotic Properties. Advances in Nutrition, 8, 155s-164s.

[67] Karaffova, V., Csank, T., Mudronova, D., Kiraly. J., Revajova, V., Gancarcikova, S., Nemcova, R., Pistl, J., Vilcek, S. and Levkut, M. (2017) Influence of Lactobacillus reuteri $\mathrm{L} 26$ Biocenol on Immune Response against Porcine Circovirus Type 2 Infection in Germ-Free Mice. Beneficial Microbes, 8, 367-378. https://doi.org/10.3920/BM2016.0114

[68] Weber, G.J., Pushpakumar, S., Tyagi, S.C. and Sen, U. (2016) Homocysteine and Hydrogen Sulfide in Epigenetic, Metabolic and Microbiota Related Renovascular Hypertension. Pharmacological Research, 113, 300-312.

[69] Yang, G., Jiang, Y., Yang, W., Du, F., Yao, Y., Shi, C. and Wang, C. (2015) Effective Treatment of Hypertension by Recombinant Lactobacillus plantarum Expressing Angiotensin Converting Enzyme Inhibitory Peptide. Microbial Cell Factories, 14, 202. https://doi.org/10.1186/s12934-015-0394-2

[70] Lecomte, V., Kaakoush, N.O., Maloney, C.A., Raipuria, M., Huinao, K.D., Mitchell, H.M. and Morris, M.J. (2015) Changes in Gut Microbiota in Rats Fed a High Fat Diet Correlate with Obesity-Associated Metabolic Parameters. PloS One, 10, e0126931. https://doi.org/10.1371/journal.pone.0126931

[71] Al Khodor, S., Reichert, B. and Shatat, I.F. (2017) The Microbiome and Blood Pressure: Can Microbes Regulate Our Blood Pressure? Frontiers in Pediatrics, 5, 138. https://doi.org/10.3389/fped.2017.00138

[72] Durgan, D.J., Ganesh, B.P., Cope, J.L., Ajami, N.J., Phillips, S.C., Petrosino, J.F., Hollister, E.B. and Bryan Jr., R.M. (2016) Role of the Gut Microbiome in Obstructive Sleep Apnea-Induced Hypertension. Hypertension (Dallas, Tex: 1979), 67, 469-474.

[73] Karbach, S.H., Schonfelder, T., Brandao, I., Wilms, E., Hormann, N., Jackel, S., Schuler, R., Finger, S., Knorr, M., Lagrange, J., et al. (2016) Gut Microbiota Promote Angiotensin II-Induced Arterial Hypertension and Vascular Dysfunction. Journal of the American Heart Association, 5. https://doi.org/10.1161/JAHA.116.003698

[74] Daliri, E.B., Oh, D.H. and Lee, B.H. (2017) Bioactive Peptides. Foods (Basel, Switzerland), 6.

[75] Kolling, Y., Salva, S., Villena, J., Marranzino, G. and Alvarez, S. (2015) Non-Viable Immunobiotic Lactobacillus rhamnosus CRL1505 and Its Peptidoglycan Improve Systemic and Respiratory Innate Immune Response during Recovery of Immunocompromised-Malnourished Mice. International Immunopharmacology, 25, 474484. https://doi.org/10.1016/j.intimp.2015.02.006

[76] Clua, P., Kanmani, P., Zelaya, H., Tada, A., Kober, A., Salva, S., Alvarez, S., Kitazawa, H. and Villena, J. (2017) Peptidoglycan from Immunobiotic Lactobacillus rhamnosus Improves Resistance of Infant Mice to Respiratory Syncytial Viral Infection and Secondary Pneumococcal Pneumonia. Frontiers in Immunology, 8, 948. https://doi.org/10.3389/fimmu.2017.00948

[77] Barbieri, N., Herrera, M., Salva, S., Villena, J. and Alvarez, S. (2017) Lactobacillus rhamnosus CRL1505 Nasal Administration Improves Recovery of T-Cell Mediated Immunity against Pneumococcal Infection in Malnourished Mice. Beneficial Microbes, 8, 393-405. https://doi.org/10.3920/BM2016.0152

[78] Panigrahi, P., Parida, S., Nanda, N.C., Satpathy, R., Pradhan, L., Chandel, D.S., 
Baccaglini, L., Mohapatra, A., Mohapatra, S.S., Misra, P.R., et al. (2017) A Randomized Synbiotic Trial to Prevent Sepsis among Infants in Rural India. Nature, 548, 407-412. https://doi.org/10.1038/nature23480

[79] Strasser, B., Geiger, D., Schauer, M., Gostner, J.M., Gatterer, H., Burtscher, M. and Fuchs, D. (2016) Probiotic Supplements Beneficially Affect Tryptophan-Kynurenine Metabolism and Reduce the Incidence of Upper Respiratory Tract Infections in Trained Athletes: A Randomized, Double-Blinded, Placebo-Controlled Trial. $\mathrm{Nu}$ trients, 8. https://doi.org/10.3390/nu8110752

[80] Yang, W.T., Yang, G.L., Shi, S.H., Liu, Y.Y., Huang, H.B., Jiang, Y.L., Wang, J.Z., Shi, C.W., Jing, Y.B. and Wang, C.F. (2017) Protection of Chickens against H9N2 Avian Influenza Virus Challenge with Recombinant Lactobacillus plantarum Expressing Conserved Antigens. Applied Microbiology and Biotechnology, 101, 4593-4603. https://doi.org/10.1007/s00253-017-8230-8

[81] Yang, W.T., Shi, S.H., Yang, G.L., Jiang, Y.L., Zhao, L., Li, Y. and Wang, C.F. (2016) Cross-Protective Efficacy of Dendritic Cells Targeting Conserved Influenza Virus Antigen Expressed by Lactobacillus plantarum. Scientific Reports, 6, 39665. https://doi.org/10.1038/srep39665

[82] Kwak, W., Kim, K., Lee, C., Lee, C., Kang, J., Cho, K., Yoon, S.H., Kang, D.K., Kim, H., Heo, J., et al. (2016) Comparative Analysis of the Complete Genome of Lactobacillus plantarum GB-LP2 and Potential Candidate Genes for Host Immune System Enhancement. Journal of Microbiology and Biotechnology, 26, 684-692. https://doi.org/10.4014/jmb.1510.10081

[83] Hayat, U., Dugum, M. and Garg, S. (2017) Chronic Constipation: Update on Management. Cleveland Clinic Journal of Medicine, 84, 397-408. https://doi.org/10.3949/ccjm.84a.15141

[84] Martinez-Martinez, M.I., Calabuig-Tolsa, R. and Cauli, O. (2017) The Effect of Probiotics as a Treatment for Constipation in Elderly People: A Systematic Review. Archives of Gerontology and Geriatrics, 71, 142-149. https://doi.org/10.1016/j.archger.2017.04.004

[85] Koppen, I.J., Velasco-Benitez, C.A., Benninga, M.A., Di Lorenzo, C. and Saps, M. (2016) Using the Bristol Stool Scale and Parental Report of Stool Consistency as Part of the Rome III Criteria for Functional Constipation in Infants and Toddlers. The Journal of Pediatrics, 177, 44-48.e41. https://doi.org/10.1016/j.jpeds.2016.06.055

[86] Zhao, Y. and Yu, Y.-B. (2016) Intestinal Microbiota and Chronic Constipation. SpringerPlus, 5, 1130. https://doi.org/10.1186/s40064-016-2821-1

[87] Wojtyniak, K., Horvath, A., Dziechciarz, P. and Szajewska, H. (2017) Lactobacillus casei Rhamnosus Lcr35 in the Management of Functional Constipation in Children: A Randomized Trial. The Journal of Pediatrics, 184, 101-105.e101. https://doi.org/10.1016/j.jpeds.2017.01.068

[88] Lim, S.M., Jang, H.M., Jang, S.E., Han, M.J. and Kim, D.H. (2017) Lactobacillus fermentum IM12 Attenuates Inflammation in Mice by Inhibiting NF-kappaBSTAT3 Signalling Pathway. Beneficial Microbes, 8, 407-419. https://doi.org/10.3920/BM2016.0156

[89] Michael, D.R., Davies, T.S., Moss, J.W.E., Calvente, D.L., Ramji, D.P. and Marchesi, J.R. (2017) The Anti-Cholesterolaemic Effect of a Consortium of Probiotics: An Acute Study in C57BL/6J Mice. Scientific Reports, 7, 2883.

[90] Tomaro-Duchesneau, C., Saha, S., Malhotra, M., Jones, M.L., Rodes, L. and Prakash, S. (2015) Lactobacillus fermentum NCIMB 5221 and NCIMB 2797 as Cholester- 
ol-Lowering Probiotic Biotherapeutics: In Vitro Analysis. Beneficial Microbes, 6, 861-869. https://doi.org/10.3920/BM2015.0021

[91] Wang, B., Chen, J., Wang, S., Zhao, X., Lu, G. and Tang, X. (2017) Lactobacillus plantarum L9 But Not Lactobacillus acidophilus LA Reduces Tumour Necrosis Factor Induced Bacterial Translocation in Caco-2 Cells. Beneficial Microbes, 8, 497-505. https://doi.org/10.3920/BM2016.0019

[92] Mencarelli, A., Cipriani, S., Francisci, D., Santucci, L., Baldelli, F., Distrutti, E. and Fiorucci, S. (2016) Highly Specific Blockade of CCR5 Inhibits Leukocyte Trafficking and Reduces Mucosal Inflammation in Murine Colitis. Scientific Reports, 6, 30802. https://doi.org/10.1038/srep30802

[93] Neurath, M.F. (2017) Current and Emerging Therapeutic Targets for IBD. Nature Reviews Gastroenterology \& Hepatology, 14, 269-278.

https://doi.org/10.1038/nrgastro.2016.208

[94] Ren, C., Zhang, Q., de Haan, B.J., Zhang, H., Faas, M.M. and de Vos, P. (2016) Identification of TLR2/TLR6 Signalling Lactic Acid Bacteria for Supporting Immune Regulation. Scientific Reports, 6, 34561. https://doi.org/10.1038/srep34561

[95] de Souza, H.S. and Fiocchi, C. (2016) Immunopathogenesis of IBD: Current State of the Art. Nature reviews Gastroenterology \& Hepatology, 13, 13-27.

https://doi.org/10.1038/nrgastro.2015.186

[96] Neyrinck, A.M., Etxeberria, U., Taminiau, B., Daube, G., Van Hul, M., Everard, A., Cani, P.D., Bindels, L.B. and Delzenne, N.M. (2017) Rhubarb Extract Prevents Hepatic Inflammation Induced by Acute Alcohol Intake, an Effect Related to the Modulation of the Gut Microbiota. Molecular Nutrition \& Food Research, 61. https://doi.org/10.1002/mnfr.201500899

[97] Chen, Z., Shi, J., Yang, X., Nan, B., Liu, Y. and Wang, Z. (2015) Chemical and Physical Characteristics and Antioxidant Activities of the Exopolysaccharide Produced by Tibetan Kefir Grains during Milk Fermentation. International Dairy Journal, 43, 15-21. https://doi.org/10.1016/j.idairyj.2014.10.004

[98] Rocha-Ramirez, L.M., Hernandez-Chinas, U., Banos-Rojas, D., Xicohtencatl-Cortes, J., Chavez-Berrocal, M.E., Rico-Rosillo, G., Kretschmer, R. and Eslava, C.A. (2016) Pet Serine Protease from Enteroaggregative Escherichia coli Stimulates the Inflammatory Response Activating Human Macrophages. BMC Microbiology, 16, 158. https://doi.org/10.1186/s12866-016-0775-7

[99] Lascurain, L., Jensen, M.K., Guthery, S.L., Holmen, J. and Deneau, M. (2016) Inflammatory Bowel Disease Phenotype in Pediatric Primary Sclerosing Cholangitis. Inflammatory Bowel Diseases, 22, 146-150. https://doi.org/10.1097/MIB.0000000000000586

[100] Azcarate-Peril, M.A., Ritter, A.J., Savaiano, D., Monteagudo-Mera, A., Anderson, C., Magness, S.T. and Klaenhammer, T.R. (2017) Impact of Short-Chain Galactooligosaccharides on the Gut Microbiome of Lactose-Intolerant Individuals. Proceedings of the National Academy of Sciences of the United States of America, 114, E367-e375. https://doi.org/10.1073/pnas.1606722113

[101] Zubiria, M.G., Gambaro, S.E., Rey, M.A., Carasi, P., Serradell, M.L.A. and Giovambattista, A. (2017) Deleterious Metabolic Effects of High Fructose Intake: The Preventive Effect of Lactobacillus kefiri Administration. Nutrients, 9. https://doi.org/10.3390/nu9050470

[102] Riaz Rajoka, M.S., Shi, J., Zhu, J., Shao, D., Huang, Q., Yang, H. and Jin, M. (2017) Capacity of Lactic Acid Bacteria in Immunity Enhancement and Cancer Prevention. Applied Microbiology and Biotechnology, 101, 35-45. 
https://doi.org/10.1007/s00253-016-8005-7

[103] Kahouli, I., Malhotra, M., Westfall, S., Alaoui-Jamali, M. and Prakash, S. (2017) The potential of Lactobacillus Probiotic Treatments in Colorectal Cancer (CRC). AACR.

[104] Lenoir, M., Del Carmen, S., Cortes-Perez, N.G., Lozano-Ojalvo, D., Munoz-Provencio, D., Chain, F., Langella, P., de Moreno de LeBlanc, A., LeBlanc, J.G. and Bermudez-Humaran, L.G. (2016) Lactobacillus casei BL23 Regulates Treg and Th17 T-Cell Populations and Reduces DMH-Associated Colorectal Cancer. Journal of Gastroenterology, 51, 862-873. https://doi.org/10.1007/s00535-015-1158-9

[105] So, S.S., Wan, M.L. and El-Nezami, H. (2017) Probiotics-Mediated Suppression of Cancer. Current opinion in Oncology, 29(1):62-72. https://doi.org/10.1097/CCO.0000000000000342

[106] Chen, X., Zhao, X., Wang, H., Yang, Z., Li, J. and Suo, H. (2017) Prevent Effects of Lactobacillus fermentum HY01 on Dextran Sulfate Sodium-Induced Colitis in Mice. Nutrients, 9. https://doi.org/10.3390/nu9060545

[107] Nakagomi, T., Cuevas, L.E., Gurgel, R.G., Elrokhsi, S.H., Belkhir, Y.A., Abugalia, M., Dove, W., Montenegro, F.M., Correia, J.B., Nakagomi, O., Cunliffe, N.A. and Hart, C.A. (2008) Apparent Extinction of Non-G2 Rotavirus Strains from Circulation in Recife, Brazil, after the Introduction of Rotavirus Vaccine. Archives of Virology, 153, 591-593. https://doi.org/10.1007/s00705-007-0028-Z

[108] Luchs, A., Cilli, A., Morillo, S.G., Cassia Compagnoli Carmona, R. and do Carmo Sampaio Tavares Timenetsky, M. (2014) Rotavirus in adults Brazil, 2004-2011: G2P[4] Domi-Nance and Potential Impact on Vaccination. Brazilian Journal of Infectious Diseases, 18.

[109] Liao, A.H., Jiang, C.B., Li, C.C., Chuang, H.C., Chiang Chiau, J.S., Chan, W.T., Yeung, C.Y., Cheng, M.L. and Lee, H.C. (2017) Combining Ultrasound and Lactobacilli Treatment for High-Fat-Diet-Induced Obesity in Mice. Journal of Animal Physiology and Animal Nutrition, 101, 703-712.

[110] Jonsson, A.L. and Backhed, F. (2017) Role of Gut Microbiota in Atherosclerosis. Nature Reviews Cardiology, 14, 79-87. https://doi.org/10.1038/nrcardio.2016.183

[111] Ma, S., We, L., Yang, H., Deng, S. and Jevnikar, A. (2017) Emerging Technologies to Achieve Oral Delivery of GLP-1 and GLP-1 Analogs for Treatment of Type 2 Diabetes Mellitus (T2DM). Canadian Journal of Biotechnology, 1. https://doi.org/10.24870/cjb.2017-000107

[112] Marcial, G.E., Ford, A.L., Haller, M.J., Gezan, S.A., Harrison, N.A., Cai, D., Meyer, J.L., Perry, D.J., Atkinson, M.A., Wasserfall, C.H., et al. (2017) Lactobacillus johnsonii N6.2 Modulates the Host Immune Responses: A Double-Blind, Randomized Trial in Healthy Adults. Frontiers in Immunology, 8, 655. https://doi.org/10.3389/fimmu.2017.00655

[113] Tiequn, B., Guanqun, C. and Shuo, Z. (2015) Therapeutic Effects of Lactobacillus in Treating Irritable Bowel Syndrome: A Meta-Analysis. Internal Medicine (Tokyo, Japan), 54, 243-249. https://doi.org/10.2169/internalmedicine.54.2710

[114] Zhang, Y., Li, L., Guo, C., Mu, D., Feng, B., Zuo, X. and Li, Y. (2016) Effects of probiotic Type, Dose and Treatment Duration on Irritable Bowel Syndrome Diagnosed by Rome III Criteria: A Meta-Analysis. BMC Gastroenterology, 16, 62. https://doi.org/10.1186/s12876-016-0470-Z

[115] Weaver, K.R., Melkus, G.D. and Henderson, W.A. (2017) Irritable Bowel Syndrome. The American Journal of Nursing, 117, 48-55. https://doi.org/10.1097/01.NAJ.0000520253.57459.01 
[116] Nasioudis, D., Beghini, J., Bongiovanni, A.M., Giraldo, P.C., Linhares, I.M. and Witkin, S.S. (2015) Alpha-Amylase in Vaginal Fluid: Association with Conditions Favorable to Dominance of Lactobacillus. Reproductive Sciences (Thousand Oaks, Calif), 22, 1393-1398. https://doi.org/10.1177/1933719115581000

[117] Mirmonsef, P., Modur, S., Burgad, D., Gilbert, D., Golub, E.T., French, A.L., McCotter, K., Landay, A.L. and Spear, G.T. (2015) Exploratory Comparison of vaginal Glycogen and Lactobacillus Levels in Premenopausal and Postmenopausal Women. Menopause (New York, NY), 22, 702-709. https://doi.org/10.1097/GME.0000000000000397

[118] Tomusiak, A., Strus, M., Heczko, P.B., Adamski, P., Stefanski, G., Mikolajczyk-Cichonska, A. and Suda-Szczurek, M. (2015) Efficacy and Safety of a Vaginal Medicinal Product Containing Three Strains of Probiotic Bacteria: A Multicenter, Randomized, Double-Blind, and Placebo-Controlled Trial. Drug Design, Development and Therapy, 9, 5345-5354. https://doi.org/10.2147/DDDT.S89214

[119] Recine, N., Palma, E., Domenici, L., Giorgini, M., Imperiale, L., Sassu, C., Musella, A., Marchetti, C., Muzii, L. and Benedetti Panici, P. (2016) Restoring Vaginal Microbiota: Biological Control of Bacterial Vaginosis. A Prospective Case-Control Study Using Lactobacillus rhamnosus BMX 54 as Adjuvant Treatment against Bacterial Vaginosis. Archives of Gynecology and Obstetrics, 293, 101-107. https://doi.org/10.1007/s00404-015-3810-2

[120] Hutt, P., Lapp, E., Stsepetova, J., Smidt, I., Taelma, H., Borovkova, N., Oopkaup, H., Ahelik, A., Roop, T., Hoidmets, D., et al. (2016) Characterisation of Probiotic Properties in Human Vaginal Lactobacilli Strains. Microbial Ecology in Health and Disease, 27, 30484. https://doi.org/10.3402/mehd.v27.30484

[121] Klatt, N.R., Cheu, R. and Birse, K. (2017) Vaginal Bacteria Modify HIV Tenofovir Microbicide Efficacy in African Women. Science, 356, 938-945.

[122] Velloza, J. and Heffron, R. (2017) The Vaginal Microbiome and Its Potential to Impact Efficacy of HIV Pre-Exposure Prophylaxis for Women. Current HIV/AIDS Reports. https://doi.org/10.1007/s11904-017-0362-z

[123] Huang, C.-H., Lin, Y.-C. and Jan, T.-R. (2017) Lactobacillus reuteri Induces Intestinal Immune Tolerance against Food Allergy in Mice. Journal of Functional Foods, 31, 44-51. https://doi.org/10.1016/j.jff.2017.01.034

[124] Yang, G., Yao, J., Yang, W., Jiang, Y., Du, J., Huang, H., Gu, W., Hu, J., Ye, L., Shi, C., et al. (2017) Construction and Immunological Evaluation of Recombinant Lactobacillus plantarum Expressing SO7 of Eimeria tenella Fusion DC-Targeting Peptide. Veterinary Parasitology, 236, 7-13. https://doi.org/10.1016/j.vetpar.2017.01.023

[125] Toshimitsu, T., Mochizuki, J., Ikegami, S. and Itou, H. (2016) Identification of a Lactobacillus plantarum Strain That Ameliorates Chronic Inflammation and Metabolic Disorders in Obese and Type 2 Diabetic Mice. Journal of Dairy Science, 99, 933-946. https://doi.org/10.3168/jds.2015-9916

[126] Chingwaru, W. and Vidmar, J. (2017) Potential of Zimbabwean Commercial Probiotic Products and Strains of Lactobacillus plantarum as Prophylaxis and Therapy against Diarrhoea Caused by Escherichia coli in Children. Asian Pacific Journal of Tropical Medicine, 10, 57-63.

[127] Moon, G.S. and Narbad, A. (2017) Monitoring of Bioluminescent Lactobacillus plantarum in a Complex Food Matrix. Korean Journal for Food Science of Animal Resources, 37, 147-152. https://doi.org/10.5851/kosfa.2017.37.1.147

[128] Jiang, Y., Yang, G., Meng, F., Yang, W., Hu, J., Ye, L., Shi, C. and Wang, C. (2016) Immunological Mechanisms Involved in Probiotic-Mediated Protection against Ci- 
trobacter Rodentium-Induced Colitis. Beneficial Microbes, 7, 397-407. https://doi.org/10.3920/BM2015.0119

[129] Jiang, Y., Ye, L., Cui, Y., Yang, G., Yang, W., Wang, J., Hu, J., Gu, W., Shi, C., Huang, H., et al. (2017) Effects of Lactobacillus rhamnosus GG on the Maturation and Differentiation of Dendritic Cells in Rotavirus-Infected Mice. Beneficial Microbes, 8, 645-656. https://doi.org/10.3920/BM2016.0157

[130] Yu, M., Qi, R., Chen, C., Yin, J., Ma, S., Shi, W., Wu, Y., Ge, J., Jiang, Y. and Tang, L. (2017) Immunogenicity of Recombinant Lactobacillus casei-Expressing F4 (K88) Fimbrial Adhesin FaeG in Conjunction with a Heat-Labile Enterotoxin A (LTAK63) and Heat-Labile Enterotoxin B (LTB) of Enterotoxigenic Escherichia coli as an Oral Adjuvant in Mice. Journal of Applied Microbiology, 122, 506-515.

[131] Li, X., Wang, E., Yin, B., Fang, D., Chen, P., Wang, G., Zhao, J., Zhang, H. and Chen, W. (2017) Effects of Lactobacillus casei CCFM419 on Insulin Resistance and Gut Microbiota in Type 2 Diabetic Mice. Beneficial Microbes, 8, 421-432.

https://doi.org/10.3920/BM2016.0167

[132] Cortes-Perez, N.G., Lozano-Ojalvo, D., Maiga, M.A., Hazebrouck, S. and Adel-Patient, K. (2017) Intragastric Administration of Lactobacillus casei BL23 Induces Regulatory FoxP3+RORgammat+ T Cells Subset in Mice. Beneficial Microbes, 8, 433-438. https://doi.org/10.3920/BM2016.0174

[133] Wong, C.B., Khoo, B.Y., Sasidharan, S., Piyawattanametha, W., Kim, S.H., Khemthongcharoen, N., Ang, M.Y., Chuah, L.O. and Liong, M.T. (2015) Inhibition of Staphylococcus aureus by Crude and Fractionated Extract from Lactic Acid Bacteria. Beneficial Microbes, 6, 129-139. https://doi.org/10.3920/BM2014.0021

[134] Wen, K., Liu, F., Li, G., Bai, M., Kocher, J., Yang, X., Wang, H., Clark-Deener, S. and Yuan, L. (2015) Lactobacillus rhamnosus GG Dosage Affects the Adjuvanticity and Protection against Rotavirus Diarrhea in Gnotobiotic Pigs. Journal of Pediatric Gastroenterology and Nutrition, 60, 834-843. https://doi.org/10.1097/MPG.0000000000000694

[135] Suebwongsa, N., Lulitanond, V., Mayo, B., Yotpanya, P. and Panya, M. (2016) Development of an Escherichia coli-Lactobacillus casei Shuttle Vector for Heterologous Protein Expression in Lactobacillus casei. Springerplus, 5, 169.

[136] Lin, R., Zhang, Y., Long, B., Li, Y., Wu, Y., Duan, S., Zhu, B., Wu, X. and Fan, H. (2017) Oral Immunization with Recombinant Lactobacillus acidophilus Expressing espA-Tir-M Confers Protection against Enterohemorrhagic Escherichia coli O157:H7 Challenge in Mice. Frontiers in Microbiology, 8.

[137] Yang, W.C., Hsu, T.C., Cheng, K.C. and Liu, J.R. (2017) Expression of the Clonostachys rosea Lactonohydrolase Gene by Lactobacillus reuteri to Increase Its Zearalenone-Removing Ability. Microbial Cell Factories, 16, 69. https://doi.org/10.1186/s12934-017-0687-8

[138] Neuman, H. and Koren, O. (2017) The Pregnancy Microbiome. Nestle Nutrition Institute Workshop Series, 88, 1-9. https://doi.org/10.1159/000455207

[139] Bond, D.M., Morris, J.M. and Nassar, N. (2017) Study Protocol: Evaluation of the Probiotic Lactobacillus fermentum CECT5716 for the Prevention of Mastitis in Breastfeeding Women: A Randomised Controlled Trial. BMC Pregnancy and Childbirth, 17. https://doi.org/10.1186/s12884-017-1330-8

[140] Fabersani, E., Abeijon-Mukdsi, M.C., Ross, R., Medina, R., Gonzalez, S. and Gauffin-Cano, P. (2017) Specific Strains of Lactic Acid Bacteria Differentially Modulate the Profile of Adipokines in Vitro. Frontiers in Immunology, 8, 266. https://doi.org/10.3389/fimmu.2017.00266 
[141] Miura, K., Ishioka, M. and Iijima, K. (2017) The Roles of the Gut Microbiota and Toll-like Receptors in Obesity and Nonalcoholic Fatty Liver Disease. Journal of $\mathrm{Ob}$ esity \& Metabolic Syndrome, 26, 86-96. https://doi.org/10.7570/jomes.2017.26.2.86

[142] Zhang, Z., Zhou, Z., Li, Y., Zhou, L., Ding, Q. and Xu, L. (2016) Isolated Exopolysaccharides from Lactobacillus rhamnosus GG Alleviated Adipogenesis Mediated by TLR2 in Mice. Scientific Reports, 6, 36083. https://doi.org/10.1038/srep36083

[143] Olaya Galan, N.N., Ulloa Rubiano, J.C., Velez Reyes, F.A., Fernandez Duarte, K.P., Salas Cardenas, S.P. and Gutierrez Fernandez, M.F. (2016) In Vitro Antiviral Activity of Lactobacillus casei and Bifidobacterium adolescentis against Rotavirus Infection Monitored by NSP4 Protein Production. Journal of Applied Microbiology, 120, 1041-1051. https://doi.org/10.1111/jam.13069

[144] Kandasamy, S., Vlasova, A.N., Fischer, D.D., Chattha, K.S., Shao, L., Kumar, A., Langel, S.N., Rauf, A., Huang, H.C., Rajashekara, G., et al. (2017) Unraveling the Differences between Gram-Positive and Gram-Negative Probiotics in Modulating Protective Immunity to Enteric Infections. Frontiers in Immunology, 8, 334. https://doi.org/10.3389/fimmu.2017.00334

[145] Gabriel, S., Dorny, P., Mwape, K.E., Trevisan, C., Braae, U.C., Magnussen, P., Thys, S., Bulaya, C., Phiri, I.K., Sikasunge, C.S., et al. (2017) Control of Taenia solium Taeniasis/Cysticercosis: The Best Way forward for Sub-Saharan Africa? Acta Trop, 165, 252-260. https://doi.org/10.1016/j.actatropica.2016.04.010

[146] Aoki, S.T., Settembre, E.C., Trask, S.D., Greenberg, H.B., Harrison, S.C. and Dormitzer, P.R. (2009) Structure of Rotavirus Outer-Layer Protein VP7 Bound with a Neutralizing Fab. Science, 324. https://doi.org/10.1126/science.1170481

[147] Novotny Nunez, I., Maldonado Galdeano, C., de Moreno de LeBlanc, A. and Perdigon, G. (2015) Lactobacillus casei CRL 431 Administration Decreases Inflammatory Cytokines in a Diet-Induced Obese Mouse Model. Nutrition, 31, 1000-1007. https://doi.org/10.1016/j.nut.2015.02.006

[148] Lindsay, K.L., Brennan, L., Kennelly, M.A., Maguire, O.C., Smith, T., Curran, S., Coffey, M., Foley, M.E., Hatunic, M., Shanahan, F., et al. (2015) Impact of Probiotics in Women with Gestational Diabetes Mellitus on Metabolic Health: A Randomized Controlled Trial. American Journal of Obstetrics and Gynecology, 212, 496.e491-411.

[149] Martínez-Porchas, M. and Vargas-Albores, F. (2017) Microbial Metagenomics in Aquaculture: A Potential Tool for a Deeper Insight into the Activity. Reviews in Aquaculture, 9, 42-56. https://doi.org/10.1111/raq.12102

[150] Ward, T.L., Knights, D. and Gale, C.A. (2017) Infant Fungal Communities: Current Knowledge and Research Opportunities. BMC Medicine, 15, 30. https://doi.org/10.1186/s12916-017-0802-z

[151] Tachedjian, G., Aldunate, M., Bradshaw, C.S. and Cone, R.A. (2017) The Role of Lactic Acid Production by Probiotic Lactobacillus Species in Vaginal Health. Research in Microbiology. https://doi.org/10.1016/j.resmic.2017.04.001

[152] Terán, V., Pizarro, P.L., Zacarías, M.F., Vinderola, G., Medina, R. and Van Nieuwenhove, C. (2015) Production of Conjugated Dienoic and Trienoic Fatty Acids by Lactic Acid Bacteria and Bifidobacteria. Journal of Functional Foods, 19, 417-425.

[153] Augustin, M.A. and Sanguansri, L. (2015) Challenges and Solutions to Incorporation of Nutraceuticals in Foods. Annual Review of Food Science and Technology, 6, 463-477. https://doi.org/10.1146/annurev-food-022814-015507

[154] Marranzino, G., Villena, J., Salva, S. and Alvarez, S. (2012) Stimulation of Macrophages by Immunobiotic Lactobacillus Strains: Influence beyond the Intestinal 
Tract. Microbiology and Immunology, 56, 771-781.

[155] Bajaj, B.K., Claes, I.J.J. and Lebeer, S. (2015) Functional Mechanisms of Probiotics. Journal of Microbiology, Biotechnology and Food Sciences, 4, 321-327. https://doi.org/10.15414/jmbfs.2015.4.4.321-327

[156] Rocha-Ramirez, L.M., Perez-Solano, R.A., Castanon-Alonso, S.L., Moreno Guerrero, S.S., Ramirez Pacheco, A., Garcia Garibay, M. and Eslava, C. (2017) Probiotic Lactobacillus Strains Stimulate the Inflammatory Response and Activate Human Macrophages. Journal of Immunology Research, 2017, 4607491.

[157] Zelaya, H., Tada, A., Vizoso-Pinto, M.G., Salva, S., Kanmani, P., Aguero, G., Alvarez, S., Kitazawa, H. and Villena, J. (2015) Nasal Priming with Immunobiotic Lactobacillus rhamnosus Modulates Inflammation-Coagulation Interactions and $\mathrm{Re}$ duces Influenza Virus-Associated Pulmonary Damage. Inflammation Research, 64, 589-602.

[158] Albarracin, L., Kobayashi, H., Iida, H., Sato, N., Nochi, T., Aso, H., Salva, S., Alvarez, S., Kitazawa, H. and Villena, J. (2017) Transcriptomic Analysis of the Innate Antiviral Immune Response in Porcine Intestinal Epithelial Cells: Influence of Immunobiotic Lactobacilli. Frontiers in Immunology, 8, 57.

https://doi.org/10.3389/fimmu.2017.00057

[159] Zelaya, H., Alvarez, S., Kitazawa, H. and Villena, J. (2016) Respiratory Antiviral Immunity and Immunobiotics: Beneficial Effects on Inflammation-Coagulation Interaction during Influenza Virus Infection. Frontiers in Immunology, 7.

[160] Jung, J.Y., Shin, J.S., Lee, S.G., Rhee, Y.K., Cho, C.W., Hong, H.D. and Lee, K.T. (2015) Lactobacillus sakei K040706 Evokes Immunostimulatory Effects on Macrophages through TLR 2-Mediated Activation. International Immunopharmacology, 28, 88-96. https://doi.org/10.1016/j.intimp.2015.05.037

[161] Kemgang, T.S., Kapila, S., Shanmugam, V.P., Reddi, S. and Kapila, R. (2016) Fermented Milk with Probiotic Lactobacillus rhamnosus S1K3 (MTCC5957) Protects Mice from Salmonella by Enhancing Immune and Nonimmune Protection $\mathrm{Me}$ chanisms at Intestinal Mucosal Level. The Journal of Nutritional Biochemistry, 30, 62-73. https://doi.org/10.1016/j.jnutbio.2015.11.018

[162] Wan, M.L.Y., Turner, P.C., Allen, K.J. and El-Nezami, H. (2016) Lactobacillus rhamnosus GG Modulates Intestinal Mucosal Barrier and Inflammation in Mice Following Combined Dietary Exposure to Deoxynivalenol and Zearalenone. Journal of Functional Foods, 22, 34-43. https://doi.org/10.1016/j.jff.2016.01.014

[163] Rouxinol-Dias, A.L., Pinto, A.R., Janeiro, C., Rodrigues, D., Moreira, M., Dias, J. and Pereira, P. (2016) Probiotics for the Control of Obesity-Its Effect on Weight Change. Porto Biomedical Journal, 1, 12-24.

[164] Quinteiro-Filho, W.M., Brisbin, J.T., Hodgins, D.C. and Sharif, S. (2015) Lactobacillus and Lactobacillus Cell-Free Culture Supernatants Modulate Chicken Macrophage Activities. Research in Veterinary Science, 103, 170-175.

https://doi.org/10.1016/j.rvsc.2015.10.005

[165] Munoz-Atienza, E., Araujo, C., Lluch, N., Hernandez, P.E., Herranz, C., Cintas, L.M. and Magadan, S. (2015) Different Impact of Heat-Inactivated and Viable Lactic Acid Bacteria of Aquatic Origin on Turbot (Scophthalmus maximus L.) Head-Kidney Leucocytes. Fish \& Shellfish Immunology, 44, 214-223. https://doi.org/10.1016/j.fsi.2015.02.021

[166] Hoseinifar, S.H., Roosta, Z., Hajimoradloo, A. and Vakili, F. (2015) The Effects of Lactobacillus acidophilus as Feed Supplement on Skin Mucosal Immune Parameters, Intestinal Microbiota, Stress Resistance and Growth Performance of Black 
Swordtail (Xiphophorus helleri). Fish \& Shellfish Immunology, 42, 533-538. https://doi.org/10.1016/j.fsi.2014.12.003

[167] Inic-Kanada, A., Stojanovic, M., Marinkovic, E., Becker, E., Stein, E., Lukic, I., Djokic, R., Schuerer, N., Hegemann, J.H. and Barisani-Asenbauer, T. (2016) A Probiotic Adjuvant Lactobacillus rhamnosus Enhances Specific Immune Responses after Ocular Mucosal Immunization with Chlamydial Polymorphic Membrane Protein C. PloS One, 11, e0157875. https://doi.org/10.1371/journal.pone.0157875

[168] Kandasamy, S., Vlasova, A.N., Fischer, D., Kumar, A., Chattha, K.S., Rauf, A., Shao, L., Langel, S.N., Rajashekara, G. and Saif, L.J. (2016) Differential Effects of Escherichia coli Nissle and Lactobacillus rhamnosus Strain GG on Human Rotavirus Binding, Infection, and B Cell Immunity. Journal of Immunology (Baltimore, Md: 1950), 196, 1780-1789. 